\title{
A Hyper-Emotion Theory of Psychological Illnesses
}

\author{
P. N. Johnson-Laird \\ Princeton University
}

\author{
Francesco Mancini \\ Associazione di Psicologia Cognitiva
}

\author{
Amelia Gangemi \\ Associazione di Psicologia Cognitiva and University of Cagliari
}

\begin{abstract}
A hyper-emotion theory of psychological illnesses is presented. It postulates that these illnesses have an onset in which a cognitive evaluation initiates a sequence of unconscious transitions yielding a basic emotion. This emotion is appropriate for the situation but inappropriate in its intensity. Whenever it recurs, it leads individuals to a focus on the precipitating situation and to characteristic patterns of inference that can bolster the illness. Individuals with a propensity to psychological illness accordingly reason better than more robust individuals, but only on topics relevant to their illness. The theory is assessed in the light of previous research, a small epidemiological study of patients, and 3 empirical studies.
\end{abstract}

Keywords: psychological illnesses, emotions, reasoning, cognitive therapy, unconscious processes

Current knowledge about psychological illnesses is comparable to the medical understanding of epidemics in the early 19th century. Physicians realized then that cholera, for example, was a specific disease, which killed about a third of the people whom it infected. What they disagreed about was the cause, the pathology, and the communication of the disease. Similarly, most medical professionals these days realize that psychological illnesses occur (cf. the Diagnostic and Statistical Manual of Mental Disorders, 4th ed., text rev. [DSM-IV-TR]; American Psychiatric Association, 2000), but they disagree about their cause and pathology. Notwithstanding the $D S M-I V-T R$, we doubt whether any satisfactory a priori definition of psychological illness can exist (cf. Wakefield, 1992) because it is a matter for theory to elucidate. However, we owe the reader at least a working definition of our topic. We take psychological illness to refer to a disorder in an individual's thinking, feeling, mood, or ability to relate to others

P. N. Johnson-Laird, Department of Psychology, Princeton University; Francesco Mancini, Scuola di Psicoterapia Cognitiva, Associazione di Psicologia Cognitiva, Rome, Italy; Amelia Gangemi, Scuola di Psicoterapia Cognitiva, Associazione di Psicologia Cognitiva, Rome, Italy, and Department of Psychology, University of Cagliari, Cagliari, Italy.

The research was made possible by National Science Foundation Grant BCS 0076287 to P. N. Johnson-Laird to study strategies in reasoning and by a grant to Francesco Mancini and Amelia Gangemi from the Scuola di Psicoterapia Cognitiva of the Associazione di Psicologia Cognitiva, Rome, Italy. We are grateful to many colleagues for help and advice: Bruno Bara, Barbara Barcaccia, Rino Capo, Ronald Comer, Vittorio Girotto, Sam Glucksberg, Geoffrey Goodwin, Andrea Gragnani, Catrinel Haught, W. Jake Jacobs, Louis Lee, Ira Noveck, Mike Oaksford, Keith Oatley, Kieron O'Connor, Claudia Perdighe, Antonella Rainone, Giuseppe Romano, Erika Sloan, and the many psychiatrists in Rome and Verona who kindly participated in our studies.

Correspondence concerning this article should be addressed to P. N. Johnson-Laird, Department of Psychology, Princeton University, Green Hall, Princeton, NJ 08544. E-mail: phil@princeton.edu that has a psychological cause, although neurophysiological factors may predispose the individual to such an illness. In terms of the $D S M-I V-T R$, the main Axis I disorders that our definition is intended to subsume include certain adjustment disorders; anxiety disorders, such as phobias, general anxiety disorder, obsessivecompulsive disorder, and posttraumatic stress disorder (but excluding substance-induced anxiety); factitious disorders in which individuals maintain a role of being sick; disorders of mood, such as reactive depression; and somatoform disorders, such as hypochondriasis. The main Axis II disorders that our definition is intended to subsume include some personality disorders, such as cognitive disorders (i.e., ways of perceiving oneself) and disorders of affectivity (i.e., in the range, intensity, lability, and appropriateness of emotional responses). For example, the definition includes cognitive and emotional processes of borderline patients when they perceive or imagine abandonment in interpersonal relationships, chronic feelings of emptiness, and inappropriate and intense anger.

Psychological illnesses, we argue, have their origins in individuals' experiences: experiences that affect their subsequent life and that may lead them to suffer to the point that they seek professional help. The human propensity to treat diseases is in no way constrained by ignorance of an illness's cause or pathology. Herink (1980) listed 250 varieties of psychotherapy from "Active analytical therapy" to "Zaraleya psychoenergetic technique," and this number has grown apace over the past 25 years. Some individuals appear to get better without any treatment, although psychotherapy tends to promote a faster recovery (see, e.g., Smith, Glass, \& Miller, 1980).

One influential approach that has an underlying theoretical rationale is cognitive therapy, or cognitive-behavioral therapy, as formulated by Beck (1976, e.g.). He doubted the role of unconscious factors in psychological illness and wrote, "Man has the key to understanding and solving his psychological disturbance within the scope of his own awareness" (Beck, 1976, p. 3). He also argued that a closer questioning of patients yields thoughts that they are 
aware of and that explain the cause of the illness. What these thoughts reveal, he said, is that the cause of psychological illnesses is faulty reasoning, including both invalid reasoning and reasoning based on misconceptions or false beliefs (Beck, 1976, chapter 4).

The notion that faulty reasoning causes psychological illness is pervasive (cf. Ellis, 1962; Maslow, 1938). The poet W. H. Auden (1977, p. 395) wrote, "The neurotic is someone who draws a false general conclusion from a particular instance." Numerous Web sites, textbooks (e.g., Wells, 1997, 2000), and self-help books (e.g., Cohen, 2003) promulgate this view (see also Brewin, 1996; Leahy, 2004). The therapy has been applied to a variety of psychological illnesses, including anxiety and depression. Its use in the treatment of depression, as described in Beck, Rush, Shaw, and Emery (1979), is more effective than antidepressant drugs (Robinson, Berman, \& Neimeyer, 1990). Yet the original theory's fundamental tenet that faulty reasoning causes psychological illnesses seems to have no robust empirical support (see, e.g., Smeets $\&$ de Jong, 2005). Indeed, this tenet may no longer be held by so many cognitive therapists as at one time (cf. A. Harvey, Watkins, Mansell, \& Shafran, 2004).

Our clinical observations suggest that patients are highly competent reasoners, at least about matters pertaining to their psychological illnesses. For example, Francesco Mancini treated a patient suffering from obsessive-compulsive disorder. She was worried that she might have contracted the HIV virus because she had touched a newspaper photograph of the late Rock Hudson, who had died from AIDS. To justify her worries, she argued as follows (translated from the Italian):

The photographer must have been close to Hudson because the photograph was a "close up." So, the photographer himself might have been contaminated. So, when he developed the negative, he could have contaminated it. The negative was in contact with the print of the photograph and so could have contaminated it. The man in charge of printing the newspaper used the photograph, and so, he could have passed its contamination on to the newspaper's printer. The printing press could have passed the contamination on to the picture in every newspaper. So, when I touched the newspaper, I too might have been contaminated.

Like other expert reasoners, this patient could construct a long chain of interconnected inferences, and she could envisage more than just obvious possibilities. She realized that her conclusion was unlikely, yet, typically for such patients, she could not reject it, and so, she obsessed about the possibility. Clinical observations of this sort led us to doubt whether faulty reasoning is the cause of psychological illnesses.

Our aim in this article is accordingly to propose a new theory. It rests on Helmholtz's (1866/1962) view of unconscious processes, on a communicative theory of emotions that distinguishes between basic and complex emotions (see, e.g., Oatley \& JohnsonLaird, 1987, 1996), and on a theory of a hierarchical brain-mind architecture (e.g., Johnson-Laird, 1983). In what follows, we first describe our theory of psychological illnesses, which characterizes their cause, their maintenance, and their signs and symptoms. We then outline the evidence supporting the theory. This evidence includes previous research, a small-scale epidemiological survey, and three experimental studies corroborating the predictions of the theory. The theory yields a taxonomy of possible psychological illnesses, and the article gives an account of the principal illnesses from obsessive-compulsive disorders to phobias.

\section{The Hyper-Emotion Theory}

The theory postulates a common cause to psychological illnesses. It attributes their onset to unconscious transitions to hyperemotional reactions. These transitions occur throughout the illness. Most patients are able to recall the events leading to their psychological illnesses - a claim borne out by a study we report later. The theory allows, however, that unconscious transitions to aberrant emotions can occur as a result of arbitrary fluctuations in any individual. The emotion is a basic one in terms of the communicative theory of emotions, and it is appropriate to the individual's evaluation of the situation but inappropriate in its intensity. Constitutional factors can determine whether this hyper-emotional reaction is merely a momentary aberration or becomes more deep seated. We now spell out the five main principles of the theory.

The first assumption posits a single cause for psychological illnesses.

1. The principle of unconscious transitions to basic emotions: Individuals acquire a sequence of unconscious transitions from a bodily feeling or cognitive evaluation to a basic emotion that is appropriate to the situation but aberrant in its intensity. The onset of a psychological illness occurs with such transitions, but they continue to occur throughout the illness.

To unpack this principle, we need to explain three concepts: cognitive evaluations, basic emotions, and unconscious transitions.

By cognition, we refer to a form of information processing carried out by the brain and underlying perception, memory and learning, and higher inferential processes such as reasoning, planning, and decision making. Cognitive evaluations can be conscious or unconscious (in Helmholtz's, 1886/1962, sense; see below).

The communicative theory of emotions (e.g., Oatley \& JohnsonLaird, 1987) postulates that emotions are internal communications in the brain that prepare organisms for various courses of action relating to the ontogeny of the species, including the expression of the emotion to others as external communications. The theory distinguishes between basic and complex emotions. Basic emotions are innate in human beings and have their own distinctive signals in the brain and in universal facial expressions (Keltner, Ekman, Gonzaga, \& Beer, 2003). The paradigm basic emotions are happiness, sadness, anger, anxiety, and disgust. One set of the brain's signals concerns basic emotions, and another set concerns bodily states such as hunger and thirst. The signals spread though the brain to mobilize bodily resources, to prepare an appropriate suite of behaviors by way of the autonomic nervous system, and to direct attention. They are a more flexible control system than innate reflexes but are more rapid than conscious reasoning. They map a diversity of cognitive evaluations into a few distinct signals, which concern significant entities in the life of the species. Hence, anxiety, which focuses attention on potential threats, such as illness in the case of hypochondria or contamination in the case of obsessive-compulsive disorder, is a prospective emotion, whereas sadness is a ruminative emotion, and so, it focuses individuals on negative aspects of their lives. The cognitive evaluations yielding basic emotions depend in part on cultural factors (Johnson-Laird \& Oatley, 2000). This point is perhaps best shown in Rozin's work 
on disgust (e.g., Rozin, 1996), but analogous effects occur with other basic emotions. As Table 1 (based on the account in Oatley \& Johnson-Laird, 1987) shows, bodily feelings and basic emotions derive from the ontogeny of social mammals and their goals.

The cognitive evaluation yielding a basic emotion can be conscious or unconscious (see, e.g., Morris, Öhman, \& Dolan, 1998). If the emotion signal, but not the cognitive evaluation, becomes conscious, then individuals feel an emotion, but they do not realize its cause. They are likely to say, for example, "I feel anxious but I don't know why." Hence, some basic emotions can be experienced without any propositional content, for instance, happiness, sadness, anger, and anxiety. Others have a known object. They include the emotion of children's attachment to their caregivers, the reciprocal emotion of parental care, sexual love, disgust, and hatred. We use "anxiety" to refer to the basic emotion that has no object and "fear" to refer to this emotion when it has a known object. The emotional signal that propagates in the brain depends on linking the emotion to the representation of its object. Individuals cannot experience, say, disgust without an object for the emotion.

Basic emotions underlie complex emotions, but complex emotions concern mental models of the self and others (Johnson-Laird \& Oatley, 2000). Individuals therefore cannot experience complex emotions without being aware of the evaluations that have precipitated them. They include such emotions as remorse, envy, and pride. Individuals feel remorse, which is sadness about an action or inaction, because they judge themselves to have violated the moral code embodied in their idealized models of their selves. There is no such thing as free-floating remorse.

The amygdala-two small almond-shaped organs in the medial temporal lobes-are critical for basic emotions. They activate the release of hormones, the suppression of pain, and various responses in the autonomic nervous system that prepare the body for emergencies. Damage to the amygdala impairs basic emotions in rats, monkeys, and humans (LeDoux, 1996). It impairs the human ability to recognize facial expressions of emotions (Calder et al., 1996). The amygdala are part of a system in which stress hormones, such as epinephrine and gluco-corticoids, enhance memory for emotional events (for a review, see Buchanan \& Adolphs, 2002). The amygdala receive information from all the senses, and LeDoux $(1996,2000)$ has discovered the neural pathways under-

Table 1

The Ontogeny of Social Mammals, Bodily Feelings, and Basic Emotions

- Eating, drinking, breathing, and the elimination of waste products: hunger, thirst, breathlessness, and feelings arising from the need to urinate, defecate, and exhale.

- The maintenance of health: feelings of bodily well-being or of weakness and nausea.

- The avoidance of noxious substances: emotion of disgust.

- The maintenance of life and meeting its goals: emotion of happiness or frustration.

- The avoidance of dangerous situations: emotion of fear or relief.

- Maintenance relations between parents and offspring: emotion of attachment and care or of sadness at loss.

- Sexual relations: feeling of sexual desire or of frustration.

- Social relations with peers, including superiors, peers, and inferiors: emotion of amity or hatred, emotion of anger or of anxiety. lying fear, leading from the perceptual input to somatic and behavioral responses. There are two routes for perceptual information to reach the amygdala. One route is rapid and goes directly from the sensory thalamus (a way station for perceptual information) to the amygdala. It bypasses the cortex, and so, it depends on only a crude evaluation. The other route is slower. It goes from the sensory thalamus to the cortex and then to the amygdala. It depends on a high-level evaluation of the perception. When individuals acquire a fear response from conditioning, the strength of the fear response correlates with the activation of the amygdala (LaBar, Gatenby, Gore, LeDoux, \& Phelps, 1998). Patients with damage to the amygdala are aware of what is happening in the conditioning, but they do not acquire the emotional response (Phelps, 2005).

The distinction between basic and complex emotions has been corroborated in neurophysiological research (Panksepp, 1998, 2005). Damasio (1994) referred to these emotions as primary and secondary, and he argued that basic emotions survive damage to the ventromedial region of the prefrontal lobes, whereas complex emotions do not. He wrote, "The prefrontal, acquired dispositional representations needed for secondary emotions are a separate lot from the innate dispositional representations needed for primary emotions. But ... the former need the latter in order to express themselves" (Damasio, 1994, p. 137). He suggested that there is still a need for reasoning, but only after the automatic evocation of emotions has reduced the number of options (Damasio, 1994, p. 173).

Following Lashley (1958), the present theory postulates that individuals are aware not of any mental processes but only of the results of these processes. Hence, even though they may be aware of the cause of an emotion, basic or complex, they cannot be aware of the process that makes the transition to the emotion itself. The transition is unconscious in Helmholtz's (1866/1962) sense that it occurs outside awareness but can underlie the construction of the contents of consciousness. The theory also postulates that only those processes yielding results of which individuals are aware have access to working memory. The function of working memory is to hold information in mind whilst individuals think about it (see, e.g., Baddeley, 1986, 2001; Miyake \& Shah, 1999; Newell, 1990). Its contents, although not necessarily all of them, are what individuals are aware of (cf. Hassin, 2005). Working memory is also the heart of computational power because it holds the intermediate results of computations (Hopcroft \& Ullman, 1979). For instance, individuals cannot handle recursive processes, such as long multiplication, or reasoning with sentential connectives without working memory or an external surrogate for it, such as a pencil and paper. Processes that do not yield conscious results are therefore computationally crude. An unconscious system can be in only one of a number of distinct states. At any one time, it is in a particular state in which it can carry out only one of a set of alternative operations, each of which produces a single result. It can remain in the same state to carry out one of the same set of operations, shift to another state, or come to a halt-perhaps with some output to another system-because there is no state to which it can make a transition. It then remains in a hiatus until it is jolted into some other state by an input from elsewhere. When there is more than one possible state to which a transition can be made, the choice need not be determined by the current state. The transitions are from one state to another. They can occur for an indefinite 
period of time. The system is not deterministic, and it is bound to make improbable transitions from time to time. However, transitions to some states may be more likely than transitions to others. Indeed, the probabilities may depend on the recent history of states through which the system has passed. Mathematicians refer to such a system as a k-limited Markov finite-state automaton. For simplicity, we refer instead to a process of unconscious transitions from one state to another.

A corollary of the principle of unconscious transitions is that the cognitive evaluations underlying basic emotions are crude in comparison to those required for complex emotions. Emotions depend on initial cognitive evaluations, but basic emotions can be triggered by evaluations of which one is not aware. These evaluations are computationally simple because they have no access to working memory. Music that refers to nothing whatsoever can nevertheless have a powerful emotional impact. These causal effects are striking: Individuals cannot explain them because they depend on crude evaluations outside awareness. According to the principle, emotional responses in psychological illnesses are similar.

The second assumption of the hyper-emotion theory concerns a lack of control.

2. The principle of no voluntary control: Individuals cannot control their basic emotions, which depend on simple cognitive evaluations.

Because the transitions to emotions are unconscious, individuals have no voluntary control over their emotions. They cannot start to feel angry merely as a result of an intention to feel angry. The best they can do is to adopt some method or thought that they know is likely to induce the emotion. Likewise, if an emotion is welling up within them, a mere intention not to feel it has no effect. Some psychologists have argued to the contrary that individuals can control their emotions. However, they seem to have meant that individuals can try to suppress the expression of their emotions or to adopt a detached attitude to upsetting events (see, e.g., Gross, 2002; Jackson, Malmstadt, Larson, \& Davidson, 2000; Lazarus \& Alfert, 1964). Individuals have some voluntary control over the expression of emotions (but cf. Ekman, 1995, for signs of leakage), and they may be able to attenuate or enhance emotions using a cognitive strategy. Yet they appear to have no control over the onset of an emotion or over which emotion they feel. At best, they can distract themselves by trying to think of something else.

The third assumption of the theory concerns the variety of psychological illnesses.

3. The ontological principle: Psychological illnesses arise from transitions to basic emotions, which derive from the ontogeny of social mammals, and so, the taxonomy of psychological illnesses depends on this ontogeny.

The earlier classification in Table 1 should therefore extend to psychological illnesses. Table 2 shows this extension and the theory's predictions about the variety of psychological illnesses.

The fourth assumption of the theory concerns predisposing factors.

4. The principle of vulnerability: Individuals vary in vulnerability to psychological illnesses depending on innately determined conditions and on adverse environments.

This principle is hardly novel, although many dualistic psychotherapists seem loath to admit its truth. It is compatible with the
Table 2

The Emotional Ontogeny and Common Psychological Illnesses

- Disorders of eating, drinking, and breathing, e.g., anorexia nervosa.

- Disorders concerning health, e.g., hypochondria.

- The avoidance of noxious substances, e.g., obsessive-compulsive disorder.

- The maintenance of life and meeting its goals, e.g., hypomania.

- The avoidance of dangerous situations, e.g., phobia.

- Maintenance relations between caregivers and children, e.g.,

depression.

- Sexual relations, e.g., psychological impotence.

- Relations with peers, e.g., social anxiety.

Note. See Table 1 for the corresponding emotions.

so-called biopsychosocial model of illnesses in general (see, e.g., Engel, 1977). We assess the evidence for the principle presently, although it is not the main focus of our research.

Unconscious transitions can have an outcome of which individuals are aware, and these outcomes can constrain their intentional actions. Similarly, when individuals are aware of the outcomes of the transitions, they reason about their hyper-emotional reactions. The fifth assumption of the theory concerns these consequences.

5. The principle of inferential consequences: Individuals focus on an aberrant basic emotion, they reason about it and its causes, and as a result, they become well practiced in reasoning about the topic, and their reasoning can maintain and generalize the illness.

If individuals feel an intense emotion about an event, real or hypothetical, then it is likely to concentrate their minds on that event. They reason about it to try to make sense of the emotion and to decide what, if anything, to do. This reasoning, however, can lead to further unconscious transitions to the emotion and, in this way, maintain or amplify their original reactions. The pattern of reasoning depends on the nature of the event and the emotion that they feel-a point to which we return in our discussion of particular psychological illnesses.

The theory needs to explain two principal phenomena. First, it must account for the persistence of psychological illnesses and their resistance to simple cures. This resistance is the fundamental paradox of psychological illnesses: Individuals who fear catastrophe fail to benefit from their continued survival (Mancini \& Gangemi, 2002; Salkovskis, 1996; Seligman, 1988). Second, the theory needs to explain how a common cause yields a diversity of psychological illnesses. The ontological principle characterizes the set of possible psychological illnesses. However, the theory needs to account for the characteristics of the different sorts of psychological illness. An analysis of all psychological illnesses would be exhausting, if not exhaustive, and so, we deal only with the most frequent illnesses in Western society: obsessive-compulsive disorder, hypochondria, phobia, and depression (see, e.g., Kessler et al., 2005). In the remainder of the article, we address each of these illnesses, and then, we assess the evidence for the theory.

\section{Cognition and Psychological Illnesses}

Our aims in this section are twofold. We review the literature on the effects of psychological illnesses on cognition. We cite only key studies because the literature is vast. We begin, however, with 
descriptions of the four representative psychological illnesses from the standpoint of the theory. We present anecdotal vignettes of each of the illnesses for readers unfamiliar with them. We then give a theoretical account of the characteristic patterns of reasoning of individuals suffering from the illnesses, an account that is based on our clinical experience with patients.

\section{Obsessive-Compulsive Disorder}

Individuals with obsessive compulsions often go through life compelled to carry out certain ritual cleansing behaviors. One patient, who is known as Ruth, devoted hours of each day to washing her hands and other such performances (see Leon, 1990). After she had used the lavatory, she scrubbed each finger individually, next the sides of her hands, and then her arms. She carried out this procedure first with soap and then with disinfectant. She next cleaned the toilet and sink in a specific way. Then, she repeated the hand-washing ritual. If she still felt contaminated, she took a shower. She washed her hands after cooking and cleaning her house, but only to the degree that these jobs made her feel dirty. She washed her hands three or four times an hour and showered six or seven times a day. Not all dirt was bad, however. She enjoyed painting pictures, and she did not object if she got spots of paint on herself. They were good dirt. The origin of her compulsions can be traced back to her childhood: She was carrying out hand washing and other rituals by the age of 5 . She was first referred to a therapist at the age of 10 .

According to the hyper-emotion theory, the immediate cause of cleansing rituals is the evaluation of certain events-household dirt, defecation, and the like — as disgusting and dangerous, and so, they elicit an unconscious transition to intense anxiety about the danger of contamination. Ruth inferred that physical contact with the disgusting substances could contaminate her and that she would be remiss not to take precautions against contamination. Like many, but not all, individuals with obsessions, she also inferred that she was at fault in putting herself at risk of contamination, and so, she also felt guilty. She could make the sensible induction that the danger was not overwhelming, and she even thought of counterexamples: No mechanism for harm existed. Yet this thought led to further inferences about possible mechanisms and, so, to examples of harm. Hence, as long as there was the slightest risk, she would have been derelict in her duty if she did not wash herself. If her washing was not complete, then the risk of contamination remained. Her mother had inculcated a regimen of hyper-cleanliness and neatness during her childhood. The acquisition of the unconscious transition was, we assume, a consequence of this regimen.

No robust evidence exists that patients with obsessive compulsions are poorer at reasoning than other individuals (see, e.g., the empirical studies of Reed, 1977). Their reasoning starts with a thought about potential danger that appears to come from nowhere, just as many thoughts do in daily life, and it contains a kernel of rational anxiety. However, it leads to an unconscious transition to extreme anxiety. The patients then focus on the improbable danger as a result of this emotion. Their excessive anxiety may lead them to overestimate the severity and the likelihood of the danger (Butler \& Mathews, 1983). Some of them also make a further transition to the complex emotion of guilt because they have carried out an action that was unnecessary and wrong in that it might harm them and others. Table 3 summarizes the theoretical account of the characteristic pattern of reasoning of patients: They search for counterexamples to the worst case scenario and then for examples of it (see Steps 3 and 4 in Table 3). This dialectical form of reasoning should lead them to accept the danger as real. Even if they can infer that the risk of contamination is small, their reasoning amplifies their anxiety. Their aim of showing that nothing endangers them has a paradoxical effect. It suggests possible mechanisms. So, they search still harder to show that no risk exists, with the aim of reducing culpability (Mancini, 2005; Mancini \& Gangemi, 2004). Thus, they go into an indefinite loop of thoughts and feelings. Pélissier and O'Connor (2002) have similarly argued that these patients have a characteristic style of reasoning because they seem unduly influenced by their own inductive arguments, but these authors found no evidence of faulty deductive reasoning. Also, van den Hout and his colleagues (Kindt, van den Hout, \& Buck, 2005; van den Hout \& Kindt, 2003) have suggested that the more such patients try to neutralize their anxiety through rituals, the more their problems increase. One consequence of the patients' style of reasoning is that their fear of contamination generalizes because they construct ever more remote mechanisms for its transmission. The newspaper with the photograph of Rock Hudson, for instance, contaminated what it touched. Ultimately, the patients may become at risk of contamination from almost anything. Yet, if a deadly virus were transmitted in the ways they envisage, their thoughts and actions would be rational.

A complete episode of rumination at its most florid can last for hours. Like any thinking, it is not deterministic. Individuals may omit a step or else obsess about it for some time. The episode may stop when a different thought comes to mind spontaneously, although the patients may then ruminate about this new thought. They can also stop from exhaustion and from the inference that they have suffered enough - the suffering occasioned by their thinking may function as expiation of the guilt. The episode may also stop if some other, more important duty intervenes. Over a series of episodes, which could last a lifetime in the absence of treatment, the risk of contamination becomes more general. That is

Table 3

The Theory's Account of the Typical Dialectical Sequence of Obsessive-Compulsive Reasoning

1. Individuals focus on danger, e.g., on an action that they have carried out. They make an unconscious transition to intense anxiety about the danger of contagious contamination.

2. They may make a further transition to the complex emotion of guilt: Their action was unnecessary and wrong because it could have harmed them and others

3. They try to infer that no possible mechanism exists that could put them at risk, and they search for counterexamples to the danger. 4. To try to exclude the danger, they think about examples of it and possible mechanisms that put them at risk. They may return to Step 3 and thus loop around between these states.

5. They may make the sensible induction that the risk of harm is unlikely. Yet its mere possibility elicits intense anxiety. They infer that they have to act to minimize the risk. If they do not act, then they and others are at risk. They may return to Step 1 and thus loop around these states. 
why Ruth came to devote so many hours of the day and night to her ritual washing.

The hyper-emotion theory is in accordance with those accounts that treat the initial intrusive thought as akin to normal preoccupations (e.g., O'Connor, 2002; Rachman, 1993; Rachman \& de Silva, 1978; Salkovskis, 1989). However, some accounts postulate radical errors in reasoning, including various sorts of fusion between thoughts and actions or events. In a fusion between thought and action, individuals think about an action, and the thought increases the probability that they will carry it out-a so-called likelihood thought-action fusion (Rachman \& Shafran, 1999; Thodarson \& Shafran, 2002). In a fusion between a thought and an event, individuals think about an event, and the thought implies its occurrence (Wells, 1997, 2000). Other sorts of fusion are said to occur in other psychological illnesses such as eating disorders (Shafran, Teachman, Kerry, \& Rachman, 1999), but fusions are taken to be characteristic of obsessive-compulsive disorders (Emmelkamp \& Aardema, 1999; O'Connor \& Aardema, 2003). However, Lee, Cougle, and Telch (2005) have demonstrated that likelihood thought-action fusions seem to be related to schizotypal traits, which may or may not co-occur with obsessive-compulsive disorder, and that moral thought-action fusions-in which unacceptable thoughts are held to be as bad as the corresponding actions-are not related to the disorder.

The hyper-emotion theory postulates that patients reason normally, but in a dialectical way, and that their many inferences about the sources of their anxiety should make them expert reasoners on the topic. As the AIDS example illustrates, they are able to construct extended sequences of inferences. Likewise, they rely on normal mechanisms to judge probabilities. According to Tversky and Koehler's (1994) support theory, the description of an event in greater detail recruits more evidence in favor of it and thus leads to a higher judged probability (see also Miyamoto, Gonzalez, $\& \mathrm{Tu}, 1995)$. Ruminations about examples of or counterexamples to a danger are similarly likely to flesh it out in more detail and thereby raise its subjective probability. The perceptual mechanisms of people suffering from obsessive-compulsive disorders appear to be normal (Constans, Foa, Franklin, \& Mathews, 1995). They tend to carry out checking or washing rituals until they feel satisfied on the basis of an emotional or somatic cue (Coles, Heimberg, Frost, \& Steketee, 2005; Wells, 2000). Szechtman and Woody (2004) have even argued that a defect in this motivational system is the principal cause of the disorder.

\section{Hypochondria}

Individuals with hypochondria go through life worried that they are ill, perhaps mortally ill. A typical case concerned a young executive, who was about to leave on a trip with his family to take up a fellowship abroad (see Singh, 1998). Shortly before the trip, he woke up one day with blurred vision. He had a sudden and overwhelming fear that he had developed multiple sclerosis. He was so worried that he made an emergency appointment with his doctor. The doctor gave him a thorough physical and an eye examination, which revealed no problems. After the patient's initial skepticism, the doctor was able to explain to him the relation between his symptoms and his worries about spending time abroad. The patient, greatly relieved, accepted the doctor's opinion. Many individuals with hypochondria, however, resist the diagnosis that they have a psychological malady, and it persists for a lifetime.

According to the $D S M-I V-T R$, hypochondria begins with certain bodily feelings. These feelings-stomach ache, slight dizziness, queasiness, and so forth-can be interpreted as signs of illness and initiate an unconscious transition to an aberrant degree of anxiety. Most individuals can experience a bout of hypochondria. They feel a pain in the chest, and they think that perhaps they are having a heart attack. Those who are robust are likely to think that it may just be indigestion, and they wait and see. The pain dissipates, and they resume life as normal. Individuals with a predisposition to worry about their health are likely to react more often. The environment can contribute to the incidence of hypochondria. If individuals consult a medical encyclopedia, a vivid description of a disease can elicit the inference that it has infected them too. Some individuals focus on bodily feelings to such a degree that the feelings elicit anxiety about mortal illness. The anxiety itself may exacerbate their symptoms. The availability of information about other cases with similar symptoms may lead them to diagnose their malady. Their predicament is analogous to Pascal's wager about the existence of God-it is rational to believe in God because nothing of consequence occurs if the belief is erroneous, but skepticism has disastrous consequences if it is erroneous. Similarly, individuals suffering from hypochondria believe that they are ill. Hence, it is rational for them to consult a doctor because nothing of consequence occurs if their belief is erroneous, but a failure to consult a doctor is disastrous if skepticism about their illness is erroneous. They go to the doctor, who fails to find anything wrong with them. They still have their bodily symptoms, and so they reject the diagnosis and search for reasons to gainsay the doctor.

One consequence of hypochondria is that patients focus on their bodily feelings to such a degree that they respond to sensations other individuals might not notice. Another consequence is frequent encounters with members of the medical profession, so that patients become experts on the disease they imagine they have. They may spend the whole day ruminating and worrying about their symptoms, and so they become expert reasoners about their illness. Their reasoning reinforces their conviction that they are ill (Salkovskis, 1996).

Table 4 summarizes the theoretical account of reasoning in hypochondria. Individuals focus on a potential danger, such as a bodily sign or feeling, and they make an unconscious transition to great anxiety that they have a serious illness. They think of possible diagnoses and search for confirmatory evidence, focusing on the worst case as a result of their own anxiety. An ever-present bodily feeling is likely to inculcate a confirmatory pattern of inferences rather than a dialectical process, and it strengthens their belief in the worst case scenario (see, e.g., Stanovich, 1999). They then infer that they should consult a doctor. If they are mistaken about their illness, no harm is done, but if they fail to consult a doctor and they have the illness, the consequences will be disastrous. In other words, they adopt a better-safe-than-sorry reasoning strategy (de Jong, Haenen, Schmidt, \& Mayer, 1998; Gilbert, 1998). Human beings tend to adopt this strategy in the face of exposure to a threat. It focuses them on the danger and leads them to search for examples confirming it. 
Table 4

The Theory's Account of the Typical Confirmatory Sequence of Hypochondriacal Reasoning

1. Individuals focus on a danger, such as a bodily feeling, which leads to an unconscious transition to intense anxiety that they are seriously ill. They may have graphic images of the spread of the illness in their body. 2. They search for evidence confirming this hypothesis from an available source of information, such as an analogy with a friend, a relative, or a case in a newspaper.

3. They infer that if they go to the doctor and they are not ill, no harm is done. However, if they fail to go to the doctor and they are ill, then the consequences will be catastrophic. They focus on the worst case. If they have already received a doctor's diagnosis that nothing is wrong with them, they infer that a further visit may convince the doctor that he or she was wrong. They may return to Step 1 and loop around these states.

4. After a diagnosis that nothing is wrong with them, they may infer that the doctor was wrong because they still have the bodily signs of illness. They search for possibilities in which the doctor's diagnosis might be wrong. These possibilities strengthen their belief that they are ill.

\section{Phobias}

Phobias, or irrational fears, fall into three main categories according to the DSM-IV-TR: Individuals with agoraphobia feel highly anxious about being trapped in places or situations that might trigger panic attacks, those with social phobia feel highly anxious about public situations in a similar way, and those with a specific phobia feel similarly about a particular object or situation, such as spiders or injections (cf. Craske, 1991). In most cases, these individuals realize that their fears are irrational. The acquisition of a transition occurs as the result of a cognitive evaluation of an event, which the individual can usually recall unless it happened in childhood. The event may be innocuous to others, but it is frightening to the individual. It may be genuinely traumatic. For example, a woman might be too frightened to fly because of the intense fear that she experienced when a plane in which she was flying was struck by lightning. Traumatic events predispose individuals to phobic reactions. For example, a New York taxi driver told one of us-whilst we were stuck in a short tunnel in Manhattan - that after he saw the collapse of the World Trade Center towers on September 11, 2001, he was about to drive into the Holland Tunnel under the Hudson River, when he was overcome with intense anxiety. He was terrified that he might get stuck there and have a panic attack. It had taken him several years to recover and to be able to drive into tunnels again. Another illustrative example is the case of an electrician who worked in Manhattan and who did some work for P. N. Johnson-Laird. As soon as the electrician got into an elevator, he was immediately overcome with anxiety that if the elevator started to go up, he would panic. The emotion was so intense that he had to get out of the elevator before the doors closed and walk up to the floor where he had a job to do. He was well aware that he had a problem and was mildly embarrassed about it. When he was away from elevators, he knew that they were not highly dangerous. Yet his anxiety rose as soon as he contemplated getting into one. He had no idea why he had this anxiety: He had just walked into an elevator one day and been overcome with anxiety when the doors started to close. He drew the obvious inference that he must avoid getting into eleva- tors because they made him anxious. Meanwhile, as his employer knew, he could not work in apartments higher than the 15th floor. Apart from this difficulty, his phobia did not prevent him from leading a happy life, and he had not sought professional help.

A traditional view of phobias is that their causes are not an objective source of risk (see, e.g., Freud, 1916-1917/1973; P. Friedman, 1959; Wolpe, 1990). A point of potential contention among theorists is whether individuals with a phobia entertain two contradictory beliefs depending on their circumstances. That is, when they are confronted with the object or situation eliciting their phobia, they believe that there is a high risk of danger, but when they are removed from it, they believe that there is a small risk of danger. The hyper-emotion theory, however, postulates that an unconscious transition leads to intense anxiety that they cannot control. Hence, if they are asked for an estimate of the risk in this state of mind, they may rate the probability of a panic attack as high-even though they continue to know that the risk of actual harm is not inordinate.

Excessive anxiety leads to overestimation of the risk (Foa \& Kozak, 1986), and so, patients rate negative events as more severe and more likely to happen to them than do control groups (Gasper \& Clore, 1998). This sort of emotional reasoning, which is common amongst those with phobic tendencies, uses an emotion as a heuristic to estimate risk (e.g., Arntz, Rauner, \& van den Hout, 1995; Gasper \& Clore, 1998; Johnson \& Tversky, 1983). Patients use their aberrant anxiety as evidence of danger, and so, those with social phobias may infer from their feelings of anxiety that they will appear stupid and incompetent to others, whereas those with panic disorder may infer from their racing pulse that they are about to have a heart attack. Arntz et al. (1995) argued that this tendency to infer danger from anxiety maintains the illness because it starts a vicious circle: Anxiety implies a threat, the threat elicits further anxiety, and so on. These phenomena are compatible with Tversky and Koehler's (1994) support theory.

Suppose that a person has to enter the sarcophagus at Chernobyl in the Ukraine. She knows that the atmosphere there is highly radioactive; she also knows that she will be wearing a protective suit and helmet and that she will not be inside the sarcophagus long enough to suffer damage from radiation. Yet suppose that she has to enter alone and that no one will be able to help her should she become indisposed for whatever reason. When she is far from Chernobyl, she contemplates the idea with only a modicum of anxiety. However, when she is poised on the threshold, she is likely to be highly anxious even though she knows that the probability of radiation damage is small. If, instead, a person is about to enter an elevator in an apartment block, he does not give the risk of being trapped a second thought. Yet, to individuals with a phobia, the door to the elevator is akin to the door to the Chernobyl sarcophagus. What they risk is not physical damage but a possible panic attack in the elevator.

Table 5 describes the theoretical account of the pattern of phobic reasoning. Individuals with agoraphobia develop fears of panic attacks as they venture away from home, and those with social phobia do so if they have to carry out some public performance. As the sequence shows, the object of a phobia is something that is usually mildly risky (see Beck, 1976), but individuals make an unconscious transition to anxiety out of proportion to the risk. This focus leads them to think in a confirmatory way. It strengthens their belief in the worst case, and so, they infer that they should 
Table 5

The Theory's Account of the Typical Confirmatory Sequence of Phobic Reasoning

1. Individuals focus on a genuine but slight danger, such as an object or situation that they evaluate as risky. The focus leads to an unconscious transition to intense anxiety. This transition may be mediated by graphic images of themselves in the dangerous situation and succumbing to a panic attack where no one can help them.

2. They search for evidence corroborating this hypothesis from an available source of information.

3. They infer the object or situation as likely to cause them stress. They can also make the sensible induction that the probability of objective harm is small but that as long as the risk exists, they should avoid the danger. They focus on the worst case. They may return to Step 1 and loop around these states.

4. They infer that they have to act to minimize the risk, e.g., by avoiding the object or situation. If they do not act, then they are at risk.

avoid the source of risk. As hypochondriac patients, they too adopt a better-safe-than-sorry strategy in reasoning about their symptoms (de Jong, et al., 1998; Gilbert, 1998).

\section{Depression}

Psychological depression, as opposed to vegetative or psychotic depression, has an onset with a sense of loss and a transition to profound sadness. The loss may be the death of a family member, and the sadness may at first be part of natural grieving. However, the loss may be less important than the emotion warrants, or the grieving may become so prolonged and have such adverse effects on other aspects of life-sleeping, eating, sexual desire-that individuals are clinically depressed. They withdraw from life, cease to look after themselves, and are full of self-reproaches. Freud (e.g., 1916-1917/1973, p. 477) argued that these selfreproaches in fact refer to another person, "the sexual object which they have lost or which has become valueless to them through its own fault." Cognitive therapists argue instead that the reproaches are self-evaluations that result from faulty inferences causing the illness (see, e.g., Beck et al., 1979). Individuals infer that they are worthless; that they have failed as parents, children, or spouses; and that their loss is irrecoverable. They may suffer remorse or regret when they compare themselves with their models of their idealized selves, and several theorists have argued that these comparisons are at the root of depression (Champion \& Power, 1995; Higgins, Klein, \& Strauman, 1985; Teasdale, Taylor, Cooper, Hayhurst, \& Paykel, 1995).

According to the hyper-emotion theory, the cause of depression is a transition to an emotion that is appropriate to the situation but is more intense and more prolonged than the situation warrants. Reasoning about the emotion and its causes, as in other psychological illnesses, comes afterward, but it has the effect of maintaining or amplifying the illness, and individuals become experts in reasoning about their faults.

As an illustrative example, consider the case of Stuart (see Sutherland, 1976). He was a boisterous extravert, leading a buoyant life as a researcher and writer, and married, with two teenage daughters. One day, his wife left him for another man. He was plunged into misery. He was unable to work and sat all day at his desk in his office with his head in his hands. He thought that he was hopeless and that his work was without value. As the months passed, he did not recover from his depression, and so, he sought treatment first from a psychoanalyst and then from a psychiatrist, at last being admitted into hospital. Even when he was released from hospital some months later, he continued to suffer bouts of depression.

Table 6 summarizes the theoretical account of depressed reasoning. The illness is likely to be triggered by a loss that would sadden most individuals, but an unconscious transition occurs to a hyper-emotion. It provokes rumination, and depending on the nature of the loss, individuals reason in ways that make sense given such an extreme emotion. Their style of reasoning is in essence confirmatory: They accrue evidence for the conclusion that the loss cannot be made good. As they think about the loss, their criteria for what would count as an acceptable substitute become more stringent - to the point that they infer that the loss is irreplaceable. Indeed, the more serious the loss, the stronger their focus on it is, and the less feasible its replacement becomes.

When robust individuals suffer a great loss, they too mourn the departed individual. They miss this person, they ruminate about their life with the person, and they may have cause to reproach themselves or the person. They too may remain marked by the loss for the rest of their lives. However, mourning has a natural life, and most individuals recover in a year or so. Their lives regain their savor, and they take up their work and social relationships with something like their old enthusiasm. They are able once more to think and to talk about the missing person without grief: He or she recedes into the past and becomes a historical figure. What occasions the recovery is the disappearance of the unconscious transition to intense sadness. In depressed individuals, however, it does not dissipate. It is as though the transition is too strong to atrophy. As a result, depressed individuals become expert at reasoning about the causes of their depression.

\section{The Effects of Psychological Illnesses on Cognition}

An obvious hypothesis about psychological illnesses is that they should depress cognitive performance in general. According to the hyper-emotion theory, however, an aberrant basic emotion should direct attention, interpretation, and judgment to those factors relevant to its cause. We now review the literature to assess this prediction.

Anxiety, as the hyper-emotion theory postulates, focuses attention on potential threats. Empirical studies have supported this prediction using a variety of procedures, such as the Stroop test

Table 6

The Theory's Account of the Typical Confirmatory Sequence of Depressive Reasoning

1. Depressed individuals focus on an individual or situation that they evaluate as lost. They make an unconscious transition to intense sadness. 2. They infer that the loss may never be made good. The possibility leads them to focus still more on the lost individual or entity. They try to infer the more favorable conclusion that the loss is not irreparable. 3 . They envisage a search for a substitute.

4. The more they focus on the lost individual or entity, the higher their standards for what would be an acceptable substitute are.

5 . They accordingly infer that the loss is irreplaceable. They may return to Step 1. 
and probe tasks. They have shown that patients suffering from anxiety and control participants with elevated states of anxiety attend selectively to stimuli posing a potential threat-at the expense of neutral stimuli (Mogg \& Bradley, 1998; Williams, Watts, MacLeod, \& Mathews, 1997). Similar studies have shown that individuals suffering from panic disorder have a bias for general threats, such as threatening words (Ehlers, Margraf, Davies, \& Roth, 1988). However, this result has been qualified by studies showing that the content of the threatening words must be related to a patient's specific fears for the bias to appear (Maidenberg, Chen, Craske, Bohn, \& Bytritsky, 1996; McNally et al., 1994; Quero, Baños, \& Botella, 1996). Individuals with social anxiety attend to social threats, such as threatening facial expressions (Bradley, Mogg, \& Millar, 2000; Gilboa-Schechtman, Foa, \& Amir, 1999). Yet, in anxiety-provoking situations, they too attend to general social threats (Chen, Ehlers, Clark, \& Mansell, 2002; Mansell \& Clark, 1999; Mansell, Clark, \& Ehlers, 2003). Their attention is also drawn to internal stimuli, such as thoughts and somatic reactions (Edelman \& Baker, 2002; Mansell et al., 2003; Woody \& Rodriguez, 2000). Individuals who have been diagnosed as suffering from generalized anxiety disorder attend selectively to both social and physical threatening words (Mathews \& MacLeod, 1986), to threatening facial expressions (Bradley, Mogg, White, Groom, \& de Bono, 1999; Mogg, Millar, \& Bradley, 2000), and to relevant internal stimuli (Ehlers \& Breuer, 1992). Likewise, individuals with a tendency to hypochondria are more likely than others to attend to information related to illness (Owens, Asmundson, Hadjistavropoulos, \& Owens, 2004). This bias occurs even when only a threat of illness has occurred (Lecci \& Cohen, 2002). Individuals suffering from obsessive compulsions are biased to attend to words concerning contamination (Tata, Leibowitz, Prunty, Cameron, \& Pickering, 1996).

Depression does not appear to be associated with an attentional bias to specific kinds of stimuli (Mogg et al., 2000; Musa, Lèpine, Clark, Mansell, \& Ehlers, 2003). With prolonged display times, however, depressed individuals tend to focus on negative information for longer than control participants, perhaps because they tend to ruminate about negative information (Compton, 2000; Gotlib \& McCabe, 1987). They may also fail to show the normal bias to avoid negative information and to attend to positive information (Gotlib, McLachlan, \& Katz, 1988; McCabe \& Gotlib, 1995; McCabe \& Toman, 2000).

Congruent with the phenomena of attention, individuals suffering from anxiety tend to make a negative interpretation of ambiguous stimuli pertinent to their illness. Hence, patients with panic disorders misinterpret ambiguous bodily sensations as catastrophic more often than do other patients or control participants (Clark, 1993; Clark \& Fairburn, 1997; Foa, 1988; J. M. Harvey, Richards, Dziadosz, \& Swindell, 1993; Kamieniecki, Wade, \& Tsourtos, 1997; Richards, Austin, \& Alvarenga, 2001; Stoler \& McNally, 1991). Patients with social phobias make negative interpretations of socially ambiguous situations and of their own social performance (Amir, Foa, \& Coles, 1998; J. M. Harvey et al., 1993; Hirsch \& Matthews, 2000; Hirsch, Matthews, Clark, \& Williams, 2003; Stopa \& Clark, 1993, 2000). Patients with hypochondria tend to identify harmless physical sensations as symptoms of disease (Barsky, Coeytaux, Sarnie, \& Cleary, 1993; Haenen, Schmidt, Schoenmakers, \& van den Hout, 1997). Individuals suffering from depression are prone to make negative self-evaluations about their achievements and their personal relations that underestimate their actual performance (Moretti \& Shaw, 1989). They also tend to generalize these evaluations to other aspects of their performance (Butler \& Mathews, 1983; Nunn, Mathews, \& Trower, 1997).

Not only do individuals suffering from anxiety disorders attend to stimuli pertinent to their illness, they also tend to be biased toward confirming their occurrence (Clark, 1993; de Jong, Mayer, \& van den Hout, 1997; de Jong, Weertman, Horselenberg, \& van den Hout, 1997; Smeets, de Jong, \& Mayer, 2000). These effects are once again specific to the content of the illness and do not occur for other sorts of material (A. Harvey et al., 2004). The same phenomenon occurs with depression (Giesler, Josephs, \& Swann, 1996; Panzarella, Alloy, Abramson, \& Klein, 1999).

In comparison with control groups, individuals suffering from psychological illness overestimate the probability that negative events will happen to them, particularly those events pertinent to their illness. Excessive anxiety leads to overestimation of risk (Foa \& Kozak, 1986), and so, patients rate negative events as more severe and more likely to happen to them than do control groups (Gasper \& Clore, 1998). Individuals use their emotions as a source of evaluations. Hence, if they feel anxious about something, then they are likely to make increased estimates of its danger-as shown in studies of individuals suffering from anxiety disordersand so, it is common amongst those with phobias and phobic tendencies (e.g., Arntz et al., 1995; Gilboa-Schechtman, Franklin, \& Foa, 2000; Johnson \& Tversky, 1983; Jones \& Menzies, 2000; Lavy, van den Hout, \& Arntz, 1993; McNally \& Foa, 1987; Öst \& Csatlos, 2000) and those with a tendency to obsessive compulsions (Davey, Startup, Zara, MacDonald, \& Field, 2003; Emmelkamp \& Aardema, 1999; Mancini, Gangemi, \& van den Hout, 2006; Rachman \& Hodgson, 1980). The same phenomenon occurs with those suffering from panic disorder (A. K. MacLeod, Tata, Kentish, \& Jacobsen, 1997; Rachman, 1994; Rachman \& Lopatka, 1986a, 1986b), hypochondria (Barsky et al., 2001; Haenen, de Jong, Schmidt, Stevens, \& Visser, 2000) and depression (Andersen, Spielman, \& Bargh, 1992; Kaney, Bowen-Jones, Dewey, \& Bentall, 1997). No need exists to postulate any special disorder in inferential mechanisms to explain these results, which fit Tversky and Koehler's (1994) support theory. Individuals with psychological illnesses are liable to think more about possible negative events pertinent to their illness than control participants, and these thoughts flesh out events in more detail and thereby raise their subjective probabilities.

The effects of psychological illnesses on memory are not clear cut, whether on conscious explicit recall or on implicit behaviors influenced by previous experiences. In comparison with control materials, stimuli relating to the specifics of an illness are better remembered by individuals prone to panic attacks (Becker, Roth, Andrich, \& Margraf, 1999; Cloitre \& Leibowitz, 1991; Lundh \& Öst, 1997; McNally, Foa, \& Donnell, 1989) and depression (Denny \& Hunt, 1992; Derry \& Kuiper, 1981; Murray, Whitehouse, \& Alloy, 1999). Other studies have revealed only small effects related to social phobia (Cloitre, Cancienne, Heimberg, Holt, \& Leibowitz, 1995; Rapee, McCallum, Melville, Ravenscroft, \& Rodney, 1994), obsessive compulsions (Ceschi, van der Linden, Dunker, Perround, \& Bredart, 2003; Radomsky \& Rachman, 1999), and generalized anxiety disorder (B. H. Friedman, Thayer, \& Borkovec, 2000). Studies of implicit memories are still 
more mixed, some showing pertinent effects, for example, for social phobia (Amir, Foa, \& Coles, 2000; Lundh \& Öst, 1997), panic disorder (Amir, McNally, Riemann, \& Clements, 1996; Cloitre, Shear, Cancienne, \& Zeitlin, 1994), generalized anxiety disorder (C. MacLeod \& McLaughlin, 1995; Mathews, Richards, \& Eysenck, 1989), and depression (Bradley, Mogg, \& Millar, 1996; Bradley, Mogg, \& Williams, 1995; Ruiz-Caballero \& González, 1994, 1997; Watkins, Vache, Verney, \& Mathews, 1996). However, other studies have failed to yield reliable effects (Baños, Medina, \& Pascual, 2001; Denny \& Hunt, 1992; Hertel \& Hardin, 1990; Lundh \& Öst, 1997; Rapee et al., 1994; Watkins, Mathews, Williamson, \& Fuller, 1992).

In summary, psychological illnesses appear not to have a general debilitating effect on cognition. Instead, their effects are consistent with pertinent basic emotions, focusing cognition on their objects (for a review of the effects of emotion per se on cognition, see, e.g., Johnson-Laird \& Oatley, 2000). These effects are more marked for the perception, interpretation, and evaluation of events than for memories of events.

\section{An Assessment of the Hyper-Emotion Theory}

The previous review provides some support for the hyperemotion theory, but the theory makes five main predictions, which are more specific, and in this section, we describe previous results corroborating them and some new studies designed to test them. The predictions are that (a) basic emotions underlie psychological illnesses, (b) the taxonomy of illnesses based on basic emotions should be universal to all cultures because basic emotions are innate, (c) individuals' susceptibility to psychological illnesses should depend on innate and environmental factors, (d) different psychological illnesses should yield different characteristic patterns of reasoning, and (e) those suffering from them should be expert reasoners at least about topics pertaining to their illness. Some of these predictions are unique to the present theory, and no other theory predicts the set as a whole. We examine each prediction in turn.

\section{Basic Emotions and Psychological Illnesses}

The theory predicts that the essential sign of a psychological illness, both at its onset and thereafter, is an unconscious transition to a basic emotion of hyper-intensity. What counts as hyperintensity? Patients themselves are often able to say that their emotions are inappropriate. They could assess this factor on a Likert-type scale running from the degree of emotion is completely appropriate to the realities of the situation to the degree of emotion is completely out of proportion to the realities of the situation (cf. Isen \& Gorglione, 1983). Those individuals with the symptoms of psychological illness should rate themselves at the latter end of the scale. Those without such symptoms should not, although they may attest that they have experienced emotions that run the full gamut of this scale.

Are hyper-emotions precursors to psychological illness? Patients themselves tell their doctors that their troubles started in this way. The electrician got into an elevator one day and was overcome with anxiety that he would be trapped. A woman who used to have a great zest for life became sad and morose and lost interest in everything that had formerly excited her (Beck, 1976, p. 13).
The man who woke up with blurred vision was terrified that he had a serious illness. A digest of case histories suggests that their onset often occurs in an experience of an inappropriately extreme emotion (see, e.g., Leon, 1990). Yet the question of whether psychological illnesses yield aberrant basic emotions is open, and so, we examine the evidence for this proposition. It falls into two main categories: brain-imaging studies of patients suffering from psychological illnesses and a small-scale epidemiological survey that we carried out with psychiatrists.

Earlier, we reviewed evidence that the amygdala mediate basic emotions, especially negative ones (Schneider et al., 1997). Hence, the theory predicts that the amygdala, or any other organs mediating relevant basic emotions, should be active whenever events elicit the signs and symptoms of a psychological illness. This prediction has been confirmed for the amygdala in brain-imaging studies. It has been corroborated in functional magnetic resonance imaging studies when stimuli have elicited anxiety in obsessivecompulsive disorder (Breiter et al., 1996), social phobia (Birbaumer et al., 1998), hypochondria (van den Heuvel et al., 2005), and posttraumatic stress disorder (Rauch et al., 2000). Likewise, activity in the amygdala positively correlates with depression of various sorts (Davidson, Pizzagalli, Nitschke, \& Putman, 2002; Yurgelun-Todd et al., 2000) and with its severity (Drevets et al., 1992). It also predicts feelings of depression in such patients (Abercrombie et al., 1998).

\section{Study 1: An Epidemiological Survey}

For obvious reasons, data are impossible to obtain at the onset of psychological illnesses, and so, to try to assess the role of basic emotions at this point in illnesses, we carried out a small-scale epidemiological survey. We asked 24 psychiatrists in Rome and Verona, Italy, to consult their records for six or so of their most recent patients whom they had diagnosed as obsessive, agoraphobic, hypochondriac, or depressed and then, using these records, to complete a questionnaire. Psychiatrists in Italy have a medical training that emphasizes the use of drugs in treatment, and most of the participants in our study had received no training in psychotherapy of any sort. The questionnaire contained 15 items concerning the diagnosis that they had made, the sex and other details of the patient, and whether the patient had any other morbid symptoms. (These items were designed to ensure that the psychiatrists used their records rather than their memories to answer the questionnaire.) The crucial questions for our purposes were whether the patient remembered the onset of the illness and, if so, the following question, which we have translated from the Italian.

Indicate which emotion the patient referred to as occurring at the onset of the illness:

\begin{tabular}{ll} 
anxiety & pride \\
guilt & fear \\
disgust & anger \\
joy & sadness \\
embarrassment & shame \\
envy & other \\
\hline
\end{tabular}

None of the psychiatrists knew the purpose of our study or the theory outlined here, but they all complied with our request. Of the 11 emotion words explicitly mentioned in the questionnaire, 5 refer to basic emotions (anxiety, disgust, fear, anger, and sadness). 
Joy can also refer to the basic emotion of happiness, but we treated it as a filler item: None of the patients ever reported joy as the emotion occurring at the onset of their illness. The remaining emotion words refer to complex emotions, and the psychiatrists were free to write any other emotion terms in the other category.

The psychiatrists provided data about 106 patients (male $=49$, female $=57$ ) whose ages ranged from 16 to 70 years (mean age 38 years) and whose illnesses had onsets ranging from when the patients were 15 to 60 years old (mean age 29 years). Table 7 summarizes the frequencies of basic and complex emotions for the four illnesses. The psychiatrists wrote only two words in the other category, and both referred to complex emotions. As Table 7 shows, there was a reliable trend for the psychiatrists to report that their patients' illnesses started with an experience of a basic emotion. The difference was reliable in an analysis of the illnesses (Wilcoxon test, $z>1.80, p<.035$ ). The difference was also significant in an analysis of the psychiatrists, who reported a mean of 3.46 onsets with basic emotions and a mean of 0.75 onsets with complex emotions (Wilcoxon test, $z>3.85, p<.0001$ ). Out of the results from 24 psychiatrists, 19 showed the predicted trend, 5 were ties, and none reported results contrary to the prediction. We also included a question about emotions subsequent to the initial ones: The results had the same overall patterns as those for the first emotion.

One exception to the prediction was the emotion of guilt, which we included in the questionnaire because of its known occurrence with obsessive-compulsive disorder. Some theorists treat guilt as a basic emotion, whereas others do not (for a review, see Ortony $\&$ Turner, 1990). According to our criteria, guilt is not a basic emotion because it normally depends on a conscious assessment of one's behavior and does not have an innate facial expression (see, e.g., Ekman, 1993). However, some patients report feeling guilty without knowing why. Hence, it does appear to be a borderline case. It may also be a subsequent emotion in the development of obsessive-compulsive disorder (see Table 3). Overall, the results bore out the theory's prediction that the onset of emotional illness tends to occur with a basic emotion rather than a complex one. The data were filtered through psychiatrists' notes of their patients' memories, but perhaps surprisingly, most of the patients did claim to remember the onset of their illness. Only about $5 \%$ of the patients had no such memories.

\section{The Taxonomy and Culture-Bound Psychological Illnesses}

The ontological principle implies that psychological illnesses arise from bodily feelings and basic emotions that depend on the ontogeny of social mammals (see Table 2). We have noticed only one potential counterexample to this taxonomy: the case of breathing. If the theory is right, then a psychological illness that concerns breathing should occur. We have searched for the existence of such a disorder and have found that some individuals do develop such psychological illnesses (see Dudley, Martin, \& Holmes, 1964; Oswald, Waller, \& Drinkwater, 1970).

The unprecedented inclusion of culture-bound syndromes in the DSM-IV-TR (see Guarnaccia \& Rogler, 1999) raises the question of whether the taxonomy is universal to all cultures. A comprehensive check is impracticable. However, could there be a psychological illness unique to a particular culture, lying outside the taxonomy in Table 2 and accordingly implicating only a complex emotion? The $D S M-I V-T R$ (Appendix I) defines a culture-bound syndrome as follows: "recurrent, locality-specific patterns of aberrant behavior and troubling experience.... Many of these patterns are indigenously considered to be 'illnesses,' or at least afflictions, and most have local names" (American Psychiatric Association, 2000, p. 898). The DSM-IV-TR lists 25 putative culture-bound syndromes, including amok, ataque de nervios, latah, and koro.

An excellent potential case of a culture-bound illness is the disorder known in Japan as taijin kyofusho (TKS). It fits the $D S M-I V-T R$ 's criteria for a culture-bound illness. Individuals suffering from the illness feel that their appearance and actions are inadequate-or, in some cases, downright offensive-in social interactions and that their acquaintances accordingly despise them, and so they feel anxious about such situations and avoid them (see, e.g., Maeda \& Nathan, 1999; Nakamura, Kitanishi, Miyake, Hashimoto, \& Kubota, 2002; Tarumi, Ichimaya, Yamada, Umesue, \& Kuroki, 2004). The illness was first identified in Japan in the early 20th century, and its diagnosis and treatment were pursued independently from Western psychiatry. TKS sufferers focus on their effects on others. They are not anxious about interacting with close family members or total strangers, only about interacting with acquaintances (Kleinknecht, Dinnel, Kleinknecht, Hiruma, \& Harada, 1997). In contrast, individuals with social phobia in Western culture focus on the effects of others on them, and public situations make them anxious.

One possibility is that Western psychiatrists might diagnose the illness more frequently if they were more familiar with its diagnostic criteria (see Nakamura et al., 2002). However, the crux is that TKS arises from a cognitive evaluation leading to the basic emotion of anxiety that is aberrant in its intensity. As we mentioned earlier, cognitive evaluations yielding basic emotions can be

Table 7

The Results of the Epidemiological Study: The Frequencies of Basic and Complex Emotions as the First Emotion at the Onset of a Psychological Illness

\begin{tabular}{|c|c|c|c|c|c|c|c|c|c|}
\hline \multirow[b]{2}{*}{ Illness } & \multicolumn{5}{|c|}{ Basic emotions } & \multicolumn{3}{|c|}{ Complex emotions } & \multirow[b]{2}{*}{ Total } \\
\hline & Anxiety & Fear & Sadness & Anger & Disgust & Guilt & Shame & Other & \\
\hline Obsessive & 14 & 0 & 0 & 0 & 2 & 7 & 2 & 0 & 25 \\
\hline Hypochondria & 13 & 6 & 0 & 0 & 0 & 0 & 0 & 0 & 19 \\
\hline Agoraphobia & 13 & 11 & 0 & 0 & 0 & 0 & 1 & 1 & 26 \\
\hline Depressive & 5 & 1 & 13 & 5 & 0 & 5 & 1 & 1 & 31 \\
\hline Total & 45 & 18 & 13 & 5 & 2 & 12 & 4 & 2 & 101 \\
\hline
\end{tabular}

Note. For 106 patients, where 5 patients were unable to recall the onset of their illnesses. 
modulated by cultural factors. The differences between TKS and social phobia in the West seem to be attributable to differences in social interactions: The Japanese see themselves as embedded in a collective network of social relations in which it is important to save face, whereas Westerners see themselves as independent and individually distinct (e.g., Nisbett, 2003). In sum, TKS is a form of social phobia, with elements of hypochondria in some cases, that is attuned to the particularities of Japanese society. We propose that the criteria for psychological illnesses in the DSM-IV-TR are culture bound in that they often reflect factors unique to Western culture.

\section{Innate and Environmental Predispositions}

The hyper-emotion theory postulates that everyone experiences unconscious transitions leading to basic emotions, and sometimes these transitions yield emotions out of proportion to the situation. In their mildest form, they are transitory and not debilitating. They may lead momentarily to irrational thoughts or actions. Individuals can live happily and successfully even if they have, say, an irrational phobia throughout their lives. Yet, in some cases, what starts as a minor emotional aberration may lead by an inferential process to further and greater misevaluations until the danger of an overwhelming emotion is extreme.

The propensity toward psychological illness depends on innate determinants of personality, as shown in studies of twins. Comparisons of monozygotic and dizygotic twins have shown that personality disorders, including tendencies both to anxiety and to depression, are heritable to some degree (Jang, McCrae, Angleitner, Riemann, \& Livesley, 1998; Livesley, Jang, \& Vernon, 1993). These innate components of personality are almost certainly dependent on multiple genes. The evidence for effects of polymorphisms of single genes yielding such propensities is still unclear (cf., e.g., Ball et al., 1997; Christian et al., 2004; Eley \& Plomin, 1997).

The implication of the twin studies is that environment also plays a part. A well-known instance of its effects is the propensity of medical students to hypochondria. Likewise, prolonged stress, such as soldiers experienced in the trenches in World War I, is conducive to psychological illness, including hysterical paralyses (see Adrian \& Yealland, 1917; Rivers, 1918). Still earlier, Snow (1858) reported a case of a woman servant who had a hysterical paralysis as a result of stress. Snow was a pioneer investigator of ether and chloroform, and the patient's symptoms continued under anesthetic, so, he was convinced that she was not malingering (see Johansen, Brody, Paneth, Rachman, \& Rip, 2003). Stress, whether social or physical, appears to be the most potent environmental factor in the cause of psychological illnesses.

\section{The Characteristic Patterns of Reasoning in Psychological Illnesses}

The theory predicts that individuals suffering from psychological illnesses reason in characteristic ways (see Tables 3-6). The main contrast in content among these four sorts of reasoning is that depression concerns a feeling of loss, whereas the other three sorts of reasoning concern sources of risk. The main contrast in form is that obsessive-compulsive reasoning is dialectical, concerning evidence both confirming and disconfirming the hypothesis of risk, although risk looms larger than security, whereas the other forms of reasoning are confirmatory. Predictions about differences in the reasoning of patients are difficult to test. On the one hand, no general and automatic procedure exists for the analysis of spontaneous reasoning. On the other hand, the contents of reasoning are likely to make obvious the nature of the psychological illness. We therefore devised a study to examine whether psychiatrists could identify the difference between the dialectical form of obsessivecompulsive reasoning and the confirmatory form of reasoning typical of hypochondria and phobia.

\section{Study 2: The Identification of Patterns of Reasoning}

We present below a pair of contrasting vignettes of patients thinking aloud about their problems. (We explain in a moment the significance of the numbers in the texts.) Both vignettes concern the same content, but according to our theory, they are characteristic of two different psychological illnesses. The reader is invited to diagnose both patients.

I. (1) I'm afraid of the little pain I'm feeling in my abdomen on the same side as my liver. It could be a symptom of cancer, a liver cancer. I remember an uncle of mine who died from liver cancer after suffering a lot. (3) But he was in his 80 s, and I'm 30, and a liver cancer at my age is rare. (4) On the other hand, it's not impossible. Moreover, it seems to me that I look unhealthy; my tongue is dirty; sometimes my mouth tastes bitter. I seem to be pale, and I could have anemia. (3) Of course, these are common symptoms, and they can be trivial. I have had them many other times. (4) But they are there, and they are not incompatible with cancer. Moreover, they don't exclude it. (3) My doctor prescribed several tests for me, and the results were all negative. (4) But the results could be those for another personsometimes laboratories mix up test tubes, or the secretary makes a mistake in writing the patient's name, or she puts the results for one person in the folder for another patient. A mistake can always occur. (3) The laboratory may be very professional, (4) but there cannot be a $100 \%$ guarantee that it didn't make a mistake. Moreover, I am the main person responsible for my own health. You can imagine how I would feel if I really had cancer and had left it too late. (5) The best I can do is to go back to my doctor

II. (1) I'm afraid of the little pain I'm feeling in my abdomen on the same side as my liver. It could be a symptom of cancer, a liver cancer. I remember an uncle of mine who died from liver cancer after suffering a lot. (2) In the beginning, his symptoms were the same as mine: He had a similar stomach ache. He didn't care, and the doctors told him that he wasn't ill. But meanwhile the cancer was spreading. Now, in the same way, the cancer may be spreading in my abdomen. Indeed, my symptoms seem to have become worse during the last few weeks. (3) Nobody believes me, and nobody takes me seriously. When they do start to treat me, it will be too late! (2) Moreover, it seems to me that I look unhealthy; my tongue is dirty; sometimes my mouth tastes bitter. I seem to be pale, and I could have anemia. What a trauma it will be for me and my family when the cancer is correctly diagnosed, and it will be too late! Afterwards, my life will be one of suffering, drugs, medical tests, checks, and surgical operations. (4) The best I can do is to go back to my doctor.

According to the theory, the first vignette has the characteristic dialectical form of an obsessive-compulsive patient, and the numbers in its text refer to the steps in Table 3, where Step 2 is an option, whereas the second vignette has the corroboratory form of 
a genuine hypochondriac, and the numbers in its text refer to the steps in Table 4.

Participants. We tested a new sample of 34 psychiatrists, all of whom practiced in Rome and participated in the study voluntarily. As we mentioned earlier, Italian psychiatrists have a standard medical training, and few, if any, in our sample had received any training in psychotherapy.

Method. We devised six matching pairs of vignettes of the sort illustrated above, but without the numbers in the text. They were based on the characteristic content of six psychological illnesses: obsessive-compulsive disorder (in two varieties, one concerning contamination and the other a compulsion to check), hypochondria, generalized anxiety, specific phobia, and paranoia. The content was as similar as possible to the thoughts of individuals suffering from these illnesses. Translations of the vignettes from the original Italian are available on this Web page: http://weblamp .princeton.edu/\%7Epsych/psychology/research/johnson_laird/index.php. One version in each vignette had the dialectical form of obsessivecompulsive disorder (see Table 3), and the other version had the corroboratory version of the other forms of illness (see Tables 4 and 5). We presented the pairs of matched vignettes to each participant in a different random order, and the order of the two sorts of matched vignettes was randomized within each presentation. The key question in the instructions was "What diagnosis would you make for each of the two patients?" We then listed as possible diagnoses the following: generalized anxiety, hypochondria, obsessive-compulsive disorder, paranoia, or specific phobia.

Results. The psychiatrists identified the dialectical vignettes as obsessive-compulsive on $83 \%$ of trials, and they performed much better than chance (binomial test, $p=.5^{34}$ ). Their performance in identifying the illness in the corroboratory form of vignettes, characteristic of other psychological illnesses, was at ceiling $(97 \%$ correct). We presume that they had experienced enough interactions with patients to make the identifications. However, they were unable to describe the cues that they had used, and their diagnoses were rapid and intuitive (cf., e.g., Hull, 1920). The fact that the vignettes were so readily identifiable supports the theory's account of the characteristic ways in which patients reason.

\section{Reasoning and Psychological Illness}

The theory predicts that individuals with a tendency toward a psychological illness should focus on their emotions and the evaluations giving rise to them and, as a result, reason more accurately about them than control participants. To test this prediction, we examined individuals with tendencies toward psychological illnesses. The crucial prediction was that these participants should reason better than control participants, but only with materials relating to their potential illnesses; with neutral content, no reliable difference in performance should occur between the two groups. This prediction is contrary to those accounts of psychological illnesses that locate their causes in faulty reasoning.

A preliminary study established the methodology. We used as simple a reasoning task as possible: The participants had to list what situations were possible and what situations were impossible given an assertion. Previous studies using this task showed that participants have a tendency to overlook possibilities (see Barres \& Johnson-Laird, 2003; Barrouillet, Grosset, \& Leças, 2000; Johnson-Laird \& Savary, 1996). Our preliminary study tested two groups of university students, who had been allocated at random to one of the two groups. One group was primed to feel guilty by having to write a description of an event from their own lives in which they felt guilty. The control group wrote no such account. A postexperimental rating task showed that the guilt-inducing task succeeded in evoking the emotion. The two groups were further subdivided in terms of whether they listed possibilities and impossibilities for sentences concerning guilt or for neutral sentences. The results corroborated the prediction: Individuals who felt guilty reasoned better than control participants, but only when they reasoned about content concerning guilt. The results could have been a consequence of the focusing effects of emotions or merely a consequence of some sort of lexical priming. Nevertheless, the procedure was successful, and so, we carried out two studies to examine the effects of the propensity to a psychological illness on reasoning. Our epidemiological survey suggested that telling comparisons should be, first, between those with a tendency toward obsessive compulsions and a control group and, second, between those with a tendency toward depression and a control group. Because both clinical groups were likely to have a tendency toward anxiety (see Table 7), the studies examined reasoning about guilt in those participants with a tendency to obsessivecompulsive disorder and reasoning about sadness in those participants with a tendency to depression.

\section{Study 3: Reasoning and a Tendency Toward Obsessive- Compulsive Disorder}

The study compared individuals with a strong tendency toward obsessive-compulsive disorder with those who had no such tendency. Each of these two groups was further subdivided into whether individuals listed possibilities for assertions designed to elicit guilt or listed possibilities for assertions that were neutral (or designed to elicit depression).

Participants. To select the participants, we gave the abridged Padua Inventory of obsessive-compulsive behaviors to 290 students at Palermo University in Palermo, Italy. This test is a 40 -item self-report inventory assessing four factors related to obsessive-compulsive behaviors (Rhéaume et al., 2000): impaired mental control, the tendency to keep checking situations, loss of control of actions, and concern about contamination. Each item is rated from 0 (not at all disturbing) to 4 (very much disturbing). The inventory has good internal consistency, test-retest reliability, and validity (Sanavio, 1988), and it discriminates between individuals with obsessive-compulsive disorder and those suffering from other psychological illnesses. From the sample that we tested, we selected the 14 students whose scores were in the top 5\% (with normalized scores of over 1.33 ) and the 14 students whose scores were in lowest $5 \%$ (with normalized scores of less than -2.20 ). The difference in their scores was reliable (Mann-Whitney $W=105.0, p<.001$ ).

Method. On each trial, the participants' task was to read a short vignette that lead to a particular assertion and then to list what was possible and what was impossible given this assertion. Given a sentence, such as

The alarm rings or I feel tired, or both,

the participants were told, "Imagine that this sentence is true. In which case, think about what's possible — one or more possibilities - in terms of the possible combinations based on whether or not the alarm rings and whether or not you feel tired. You may think that there is only one possible combination or more than one. In this last case, list each possibility on a different line." The correct performance would be to list the following three fully explicit possibilities, which make clear the status of both clauses in the disjunction in each possibility.

Alarm rings. $\quad$ I don't feel tired.

Alarm doesn't ring. I feel tired.

Alarm rings. I feel tired. 
The following case should be listed as impossible.

\section{Alarm doesn't ring. I don't feel tired.}

Unless participants are told to list fully explicit possibilities, they tend to list those possibilities compatible with mental models of assertions, that is, they list clauses in assertions, whether affirmative or negative, only when they are true in a possibility (see, e.g., Johnson-Laird \& Savary, 1996). Hence, they are likely to list the following three true possibilities for the disjunction above.

\section{Alarm rings.}

\section{I feel tired.}

Alarm rings. I feel tired.

We refer to these possibilities as corresponding to the mental models of the disjunction. The distinction between fully explicit possibilities and mentalmodel possibilities also applies in listing what is impossible for conjunctive assertions.

The two principal groups (those with a tendency to obsessive compulsions and those with no such tendency) were further subdivided into two. In the first case, the participants had to list possibilities for assertions with content designed to elicit an emotion of guilt. The story preceding the assertion concerned the culpability of the protagonist, for example,

Suppose I am at my house with some friends. We decide to join some other friends in a bar. We leave the house joking amongst ourselves, but I forget to close the bathroom window.

The sentence for which possibilities had to be listed was as follows.

The burglar alarm rings and I feel guilty.

In the second case, the participants had to list possibilities either with sentences concerning depression, for example,

The burglar alarm rings and I feel depressed,

or with neutral assertions. The participants in each group carried out the task four times in a different random order: Two of the stories had a test assertion based on and, and two of the stories had a test assertion based on or.

Results. Individuals with a tendency to obsessive compulsions who encountered a story likely to engage a feeling of guilt listed more correct fully explicit possibilities (63\% of the possibilities) than the control participants (23\% of the possibilities; MannWhitney $W=15.5, p<.02$ ). However, when the story and assertion had either content concerning depression or neutral content, no reliable difference occurred between the obsessive group and the control group (e.g., the two groups listed $7 \%$ and $19 \%$ fully explicit true possibilities, respectively). The participants with a tendency to obsessive compulsions likewise listed as impossible more correct fully explicit possibilities in which they were not guilty (62\% of the possibilities) than their control counterparts ( $25 \%$ of possibilities; Mann-Whitney $W=16.0, p<.02$ ). However, when the story and assertion had either content concerning depression or neutral content, there was no reliable difference between the obsessive group and the control group (e.g., the two groups listed $26 \%$ and $13 \%$ false possibilities, respectively). We also scored the groups in terms of the percentages of correct possibilities corresponding to mental models. The percentages increased, but with the same pattern of statistical significances. We conclude that a predisposition to obsessive-compulsive disorder can enhance reasoning about content relevant to the disorder.

\section{Study 4: The Reasoning of Individuals With a Tendency to Depression}

The aim of this study was to determine whether individuals with a tendency to depression also showed a comparable increase in their ability to reason about materials that concern depressing matters. That is, they should reason more accurately than control participants who were not depressed, but only with materials concerning their propensity to depression.

Participants. We gave the Beck Depression Inventory (Beck et al., 1979) to a new sample of 370 students at the University of Palermo. The inventory is a 21-item self-report scale, which focuses on the cognitive symptoms of depression. Each item is scored on a scale from 0 to 3, with higher scores indicating a greater severity of depression. The inventory has good internal consistency with both psychiatric and nonpsychiatric samples and good concurrent validity with other measures of depression. We selected from our sample the 18 individuals who scored in the highest $5 \%$ for depression (with normalized scores greater than 2.9) and the 22 individuals who scored in the lowest $5 \%$ (with normalized scores of less than 1.3). The difference in their scores was reliable (Mann-Whitney $W=$ 253.0, $p<.001$ ). These 40 participants, who had a mean age of just under 24 years, carried out the study.

Method. The design, procedure, and materials were identical to the preceding study, and all that differed were the participants and the allocation of materials to them. As in the previous study, each of these two groups was further subdivided depending on whether they listed possibilities for assertions designed to engage depression (e.g., "The burglar alarm rings and I feel depressed") or control materials that concerned either guilt (e.g., "The burglar alarm rings and I feel guilty") or were neutral in content. Each participant carried out the task four times: Two of the stories had a test assertion based on and, and two of the stories had a test assertion based on $o$.

Results. Individuals with a tendency to depression who encountered a story likely to engage a feeling of depression listed more correct fully explicit possibilities (66\% of the possibilities) than the control participants (only $27 \%$ of the possibilities; MannWhitney $W=36.0, p<.005)$. When the story and assertion had either content concerning guilt or neutral content, no reliable difference occurred between the two groups in the listing of possibilities (e.g., the two groups listed $21 \%$ and $16 \%$ true possibilities, respectively). The participants with a tendency to depression likewise listed as impossible more correct cases in which they were not depressed (53\% of the possibilities) then the control participants (27\% of possibilities; Mann-Whitney $W=36.0, p<$ $.005)$. However, when the story and assertion had either content concerning guilt or neutral content, there was no reliable difference between the two groups in the listing of impossibilities (e.g., they listed $26 \%$ and $18 \%$ true possibilities, respectively). As in the previous study, we also scored the groups in terms of the percentages of correct possibilities corresponding to mental models. The percentages increased but had the same pattern of statistical significances, except that the difference between the two groups in listing impossible cases in which they were not depressed was only marginally reliable. A tendency toward depression accordingly improves reasoning, but only with content relevant to the illness.

The evidence that we have presented in this section supports the hyper-emotion theory. Individuals with a propensity toward psychological illnesses reason better about topics pertinent to the illness than individuals without such a propensity. This effect disappears with other sorts of content, either neutral content or content relevant to a different psychological illness. Such effects 
have a family resemblance to those of mood on memory. Individuals who are happy tend to recall more pleasant events than unpleasant events from their childhood (see, e.g., Bower, 1981). In reasoning, however, individuals have to generate novel possibilities, and so the effect is not quite the same. In our view, combinations of possibilities, which are constructed unconsciously, are more likely to be entertained consciously when they are pertinent to individuals' emotions and to matters about which they have thought in great detail in the past.

\section{General Discussion}

Individuals suffering from psychological illnesses experience emotions of an inappropriate intensity. A patient says, for instance, "I feel extreme anxiety about getting into an elevator because I may have a panic attack and be trapped there." Almost anyone can think, "It is possible that I could be trapped in an elevator and panic." However, this thought does not engender extreme anxiety. On the contrary, it is momentary, and one brushes it aside. So, what is it that makes the patient so anxious? The patient cannot say. In the past, this vacuum has been filled in various ways. Psychoanalysts have filled it with appeals to repressed desires that are often remote from the immediate object of the emotions (Freud, 1916-1917/1973). Some cognitive therapists, however, doubt the role of unconscious factors. The therapist should persist, and patients should at length reveal the source of the illness in faulty inferences, which are either invalid or based on false beliefs (Beck, 1976).

The hyper-emotion theory offers a different explanation. In a nutshell, it postulates that individuals sometimes make a cognitive evaluation-of whose content they may be aware - that yields an unconscious transition to a basic emotion of hyper-intensity. Depending on constitutional and environmental factors, the episode may be short-lived or may be amplified into a full-fledged psychological illness, especially by individuals' inferences about the object of the emotion. The theory is accordingly based on five main theoretical principles. The first two principles concern the role of basic emotions and their uncontrollable nature. Psychological illnesses are a result of a sequence of unconscious transitions from a bodily feeling or cognitive evaluation to a basic emotion that is appropriate to the situation but aberrant in its intensity, and individuals have no control over this emotion. Their inability either to introspect on the cause of the intensity of the emotion or to control it is normal. No one can introspect on the transition yielding an emotion: It is as unconscious as, say, the process yielding the perception of depth (Helmholtz, 1866/1962). Likewise, no one has direct voluntary control of an emotion. The onset of the illness occurs with such transitions, but they continue to occur throughout the illness. Our epidemiological study corroborated the claim that the onset of psychological illnesses concerns basic emotions rather than complex emotions. The same conclusion can be drawn from a number of recent brain-imaging studies of psychological illnesses, which we have reviewed above and which examined the activation of the amygdala. The amygdala are known to underlie basic emotions and are active during the emotional responses that occur in patients suffering from psychological illnesses.

The third principle postulates that unconscious transitions can relate to anything in the emotional ontogeny of human beings, which is similar to the ontogeny of social mammals in general. It follows as a corollary that just as basic emotions are innate and universal to all cultures, psychological illnesses should also be universal and relate to the taxonomy deriving from basic emotions (see Table 2). One salient putative counterexample to the theory is the set of so-called culture-bound syndromes. Because culture can influence the cognitive evaluations yielding basic emotions, we have argued that it influences all psychological illnesses. A true counterexample would therefore be a psychological illness that implicates a complex emotion dependent on culture. The example of the Japanese illness TKS is a candidate case of a culture-bound illness. However, we have argued that it is merely a social phobia reflecting the particularities of Japanese society. Insofar as any psychological illness is universal, we suppose that it reflects universals in social life from one culture to another.

The fourth principle is that individuals differ in their vulnerability to psychological illnesses depending on both innate and environmental factors. This principle is hardly unique to the present theory, although not all accounts accept that such factors matter. The evidence supports this principle.

The fifth and final principle postulates that individuals reason about aberrant emotions and their causes. One consequence is that their reasoning may increase their emotional responses-especially in the cases of obsessive-compulsive disorder, hypochondria, and depression-or may lead to actions that shun anxietyprovoking situations-especially in the case of phobias. Reasoning can thus be a source of positive feedback that amplifies emotional responses and enlarges the circumstances that trigger the unconscious transition. Another consequence is that individuals should develop characteristic patterns of reasoning depending on the nature of their illness. It is difficult to test this consequence, but a study showed that psychiatrists were able to identify the dialectical pattern of obsessive-compulsive reasoning and the corroboratory pattern of other psychological illnesses.

Given the hyper-emotional reactions of patients, their reasoning is not necessarily at fault and does not seem to cause their illness. As the fourth principle postulates, they focus on their emotions and the situations that provoke them. This focus is reasonable given the intensity of their emotions. Their inferences are rational, and as a result of prolonged rumination, patients become expert reasoners about those matters pertaining to their illnesses. The principle also predicts that if individuals with psychological illnesses or a propensity toward them focus on matters pertinent to their emotion, their reasoning should be better than both the reasoning of normal individuals on the same topic and their own reasoning on other topics. This prediction is crucial because it violates the basic tenet in Beck's formulation of cognitive therapy, namely, that faulty reasoning is the cause of psychological illnesses: "The patient frequently detours logic and leaps to arbitrary inferences, overgeneralizations, and magnifications" (Beck, 1976, p. 245). We have reported studies that corroborate our theory's prediction for participants predisposed to obsessive-compulsive disorder and also for those predisposed to depression.

What would show the hyper-emotion theory to be false? It could be refuted by various observations about the illnesses within its purview. It could be refuted if, say, patients had psychological illnesses concerning complex emotions, if their illnesses were not associated with increased activation of the amygdala or other brain organs mediating relevant basic emotions, if they reasoned no 
better about topics relevant to their illnesses than about other topics, if they could explain why their emotions were aberrant in intensity, if a window onto their unconscious processes revealed that the objects of their emotions were after all of a Freudian nature, if their illnesses had quite a different basis from one culture to another, or if no one apart from patients ever experienced hyper-emotional reactions.

Psychological illnesses have a long history in both theory and therapy. One reason for their intractability, according to our account, is that the transition to an inappropriate emotion is unconscious. Individuals cannot be aware of it, and they cannot control it. They can tell therapists that they are frightened of a panic attack in an elevator, that they need to wash in a precise way to prevent contamination, or that their blurred vision is a sign of sclerosis. They can tell therapists the cause of their emotions, but they cannot explain why they feel them to a degree that is out of proportion to the situation. This hiatus has led to myriad diagnoses and therapies. However, if the present theory is correct, psychological illnesses are merely transitions from normal life to abnormal emotions. The therapeutic goal should be to undo the transitions and to undo otherwise expert patterns of inference that amplify their effects.

\section{References}

Abercrombie, H. C., Schaefer, S. M., Larson, C. L., Oakes, T. R., Lindgren, K. A., Holden, J. E., et al. (1998). Metabolic rate in the right amygdala predicts negative affect in depressed patients. NeuroReport, 9, 33013307.

Adrian, E. D., \& Yealland, L. R. (1917, June 9). The treatment of some common war neuroses. The Lancet, 189(4893), 867-872.

American Psychiatric Association. (2000). Diagnostic and statistical manual of mental disorders (4th ed., text rev.). Washington, DC: Author.

Amir, N., Foa, E. B., \& Coles, M. E. (1998). Negative interpretation bias in social phobia. Behaviour Research and Therapy, 36, 945-957.

Amir, N., Foa, E. B., \& Coles, M. E. (2000). Implicit memory bias for threat-relevant information in generalized social phobia. Journal of Abnormal Psychology, 109, 713-720.

Amir, N., McNally, R., Riemann, B. C., \& Clements, C. (1996). Implicit memory bias for threat in panic disorder: Application of the "white noise" paradigm. Behaviour Research and Therapy, 34, 157-162.

Andersen, S. M., Spielman, L. A., \& Bargh, J. A. (1992). Future-events schemas and certainty about the future: Automaticity in depressives' future-event predictions. Journal of Personality and Social Psychology, 63, 711-723.

Arntz, A., Rauner, M., \& van den Hout, M. (1995). "If I feel anxious, there must be danger": Ex-consequentia reasoning in inferring danger in anxiety disorder. Behaviour Research and Therapy, 33, 917-925.

Auden, W. H. (1977). The English Auden: Poems, essays and dramatic writings 1927-1939. London: Faber \& Faber.

Baddeley, A. (1986). Working memory. New York: Oxford University Press.

Baddeley, A. (2001). Is working memory still working? American Psychologist, 56, 849-864.

Ball, D., Hill, L., Freeman, B., Eley, T. C., Strelau, J., Riemann, R., et al. (1997). The serotonin transporter gene and peer-rated neuroticism. NeuroReport, 8, 1301-1304.

Baños, R. M., Medina, P. M., \& Pascual, J. (2001). Explicit and implicit memory bias in depression and panic disorder. Behaviour Research and Therapy, 39, 61-74.

Barres, P., \& Johnson-Laird, P. N. (2003). On imagining what is true (and what is false). Thinking \& Reasoning, 9, 1-42.
Barrouillet, P., Grosset, N., \& Leças, J. F. (2000). Conditional reasoning by mental models: Chronometric and developmental evidence. Cognition, 75, 237-266.

Barsky, A. J., Ahern, D. K., Bailey, E. D., Saintfort, R., Liu, E. B., \& Peekna, H. M. (2001). Hypochondriacal patients' appraisal of health and physical risks. American Journal of Psychiatry, 158, 783-787.

Barsky, A. J., Coeytaux, R. R., Sarnie, M. K., \& Cleary, P. D. (1993). Hypochondriacal patient's beliefs about good health. American Journal of Psychiatry, 150, 1085-1089.

Beck, A. T. (1976). Cognitive therapy and the emotional disorders. New York: Meridian.

Beck, A. T., Rush, A., Shaw, B., \& Emery, G. (1979). Cognitive therapy of depression. New York: Guilford Press.

Becker, E. S., Roth, W. T., Andrich, M., \& Margraf, J. (1999). Explicit memory in anxiety disorder. Journal of Abnormal Psychology, 108, $153-163$.

Birbaumer, N., Grodd, W., Diedrich, O., Klose, U., Erb, M., Lotze, M., et al. (1998). fMRI reveals amygdala activation to human faces in social phobics. NeuroReport, 9, 1223-1226.

Bower, G. H. (1981). Mood and memory. American Psychologist, 36, $129-148$.

Bradley, B. P., Mogg, K., \& Millar, N. (1996). Implicit memory bias in clinical and non-clinical depression. Behaviour Research and Therapy, 34, 865-879.

Bradley, B. P., Mogg, K., \& Millar, N. (2000). Covert and overt orienting of attention to emotional faces in anxiety. Cognition \& Emotion, 14, 789-808.

Bradley, B. P., Mogg, K., White, J., Groom, C., \& de Bono, J. (1999). Attentional bias for emotional faces in generalised anxiety disorder. British Journal of Clinical Psychology, 38, 267-278.

Bradley, B. P., Mogg, K., \& Williams, R. (1995). Implicit and explicit memory for emotion-congruent information in clinical depression and anxiety. Behaviour Research and Therapy, 33, 755-770.

Breiter, H. C., Rauch, S. L., Kwong, K. K., Baker, J. R., Weisskoff, R. M., Kennedy, D. N., et al. (1996). Functional magnetic resonance imaging of symptom provocation in obsessive-compulsive disorder. Archives of General Psychiatry, 53, 595-606.

Brewin, C. R. (1996). Theoretical foundations of cognitive-behavior therapy for anxiety and depression. Annual Review of Psychology, 47, 33-57.

Buchanan, T. W., \& Adolphs, R. (2002). The role of the human amygdala in emotional modulation of long-term declarative memory. In S. C. Moore \& M. Oaksford (Eds.), Emotional cognition: From brain to behaviour (pp. 9-34). Amsterdam: John Benjamins.

Butler, G., \& Mathews, A. (1983). Cognitive processes in anxiety. Behavior Research and Therapy, 5, 51-62.

Calder, A. J., Young, A. W., Rowland, D., Perrett, D., Hodges, J. R., \& Etcoff, N. L. (1996). Facial emotion recognition after bilateral amygdala damage: Differentially severe impairment of fear. Cognitive Neuropsychology, 13, 699-745.

Ceschi, G., van der Linden, M., Dunker, D., Perround, A., \& Bredart, S. (2003). Further exploration of memory bias in compulsive washers. Behaviour Research and Therapy, 41, 737-748.

Champion, L. A., \& Power, M. J. (1995). Social and cognitive approaches to depression: Towards a new synthesis. British Journal of Clinical Psychology, 34, 485-503.

Chen, Y. P., Ehlers, A., Clark, D. M., \& Mansell, W. (2002). Patients with generalized social phobia direct their attention away from faces. Behaviour Research and Therapy, 40, 677-687.

Christian, P., Jacob, C. P., Strobel, A., Hohenberger, K., Ringel, T., Gutknecht, L., et al. (2004). Association between allelic variation of serotonin transporter function and neuroticism in anxious cluster $\mathrm{C}$ personality disorders. American Journal of Psychiatry, 161, 569-572. 
Clark, D. M. (1993). Cognitive mediation of panic attacks induced by biological challenge tests. Behaviour Research and Therapy, 15, 75-84.

Clark, D. M., \& Fairburn, C. G. (1997). Science and practice of cognitive behaviour therapy. Oxford, England: Oxford University Press.

Cloitre, M., Cancienne, J., Heimberg, R. G., Holt, C. S., \& Leibowitz, M. R. (1995). Memory bias does not generalise across in anxiety disorders. Behaviour Research and Therapy, 33, 305-307.

Cloitre, M., \& Leibowitz, M. R. (1991). Memory bias in panic disorder: An investigation of the cognitive avoidance hypothesis. Cognitive Therapy and Research, 15, 371-386.

Cloitre, M., Shear, M. K., Cancienne, J., \& Zeitlin, S. B. (1994). Implicit and explicit memory for catastrophic associations to bodily sensations words in panic disorder. Cognitive Therapy and Research, 18, 225-240.

Cohen, E. D. (2003). Self-control through the power of reason: What would Aristotle do? New York: Prometheus Books

Coles, M. E., Heimberg, R. G., Frost, R. O., \& Steketee, G. (2005). Not just right experiences and obsessive-compulsive features: Experimental and self-monitoring perspectives. Behaviour Research and Therapy, 43, 153-167.

Compton, R. J. (2000). Ability to disengage attention predicts negative affect. Cognition \& Emotion, 14, 401-415.

Constans, J. L., Foa, E. B., Franklin, M. E., \& Mathews, A. (1995). Memory for actual and imagined events in OC checkers. Behaviour Research and Therapy, 33, 665-671.

Craske, M. G. (1991). Phobic fear and panic attacks: The same emotional state triggered by different cues? Clinical Psychology Review, 11, 599620

Damasio, A. R. (1994). Descartes' error: Emotion, reason, and the human brain. New York: Grosset/Putnam.

Davey, G. C. L., Startup, H. M., Zara, A., MacDonald, C. B., \& Field, A. P. (2003). The perseveration of checking thoughts and mood-as-input hypothesis. Journal of Behavior Therapy and Experimental Psychiatry, 34, $141-160$.

Davidson, R. J., Pizzagalli, D., Nitschke, J. B., \& Putman, K. (2002). Depression: Perspective from affective neuroscience. Annual Review of Psychology, 53, 545-574.

de Jong, P. J., Haenen, M., Schmidt, A., \& Mayer, B. (1998). Hypochondriasis: The role of fear-confirming reasoning. Behaviour Research and Therapy, 36, 65-74.

de Jong, P. J., Mayer, B., \& van den Hout, M. (1997). Conditional reasoning and phobic fear: Evidence for a fear-confirming reasoning pattern. Behaviour Research and Therapy, 35, 507-516.

de Jong, P. J., Weertman, A., Horselenberg, R., \& van den Hout, M. (1997). Deductive reasoning and pathological anxiety: Evidence for a relatively strong "belief bias" in phobic subjects. Cognitive Therapy and Research, 21, 647-662.

Denny, E. B., \& Hunt, R. R. (1992). Affective valence and memory in depression: Dissociation of recall and fragment completion. Journal of Abnormal Psychology, 101, 575-580.

Derry, P. A., \& Kuiper, N. A. (1981). Schematic processing and selfreference in clinical depression. Journal of Abnormal Psychology, 90, 286-297.

Drevets, W. C., Videen, T. O., Price, J. L., Preskorn, S. H., Carmichael, S. T., \& Raichle, M. E. (1992). A functional anatomical study of unipolar depression. Journal of Neuroscience, 12, 3628-3641.

Dudley, D. L., Martin, C. J., \& Holmes, T. H. (1964). Psychophysiologic studies of pulmonary ventilation. Psychosomatic Medicine, 26, 645660

Edelman, R. J., \& Baker, S. R. (2002). Self reported and actual physiological responses in social phobia. British Journal of Clinical Psychology, 41, 1-14.

Ehlers, A., \& Breuer, P. (1992). Increased cardiac awareness in panic disorder. Journal of Abnormal Psychology, 101, 371-382.

Ehlers, A., Margraf, J., Davies, S., \& Roth, W. T. (1988). Selective processing of threat cues in subjects with panic attacks. Cognition \& Emotion, 2, 201-219.

Ekman, P. (1993). Facial expression and emotion. American Psychologist, 48, 384-392.

Ekman, P. (1995). Telling lies: Clues to deceit in the marketplace, politics, and marriage. New York: Norton.

Eley, T. C., \& Plomin, R. (1997). Genetic analyses of emotionality. Current Opinion in Neurobiology, 7, 279-284.

Ellis, A. (1962). Reason and emotion in psychotherapy. New York: Lyle Stuart.

Emmelkamp, P. M. G., \& Aardema, F. (1999). Metacognition, specific obsessive-compulsive beliefs and obsessive-compulsive behaviour. Clinical Psychology and Psychotherapy, 6, 139-145.

Engel, G. L. (1977, April 8). The need for a new medical model: A challenge for biomedicine. Science, 196, 129-136.

Foa, E. B. (1988). What cognitions differentiate panic disorder from other anxiety disorders? In I. Hard \& H.-U. Wittchen (Eds.), Panic and phobias 2 (pp. 159-166). New York: Springer-Verlag.

Foa, E. B., \& Kozak, M. R. (1986). Emotional processing of fear: Exposure to corrective information. Psychological Bulletin, 99, 20-35.

Freud, S. (1973). Introductory lectures on psychoanalysis (J. Strachey, Trans.). Harmondsworth, England: Penguin. (Original work published 1916-1917)

Friedman, B. H., Thayer, J. F., \& Borkovec, T. D. (2000). Explicit memory bias for threat words in generalized anxiety disorder. Behaviour Therapy, 31, 745-756.

Friedman, P. (1959). The phobias. In S. Arieti (Ed.), American handbook of psychiatry (pp. 292-305). New York: Basic Books.

Gasper, K., \& Clore, G. L. (1998). The persistent use of negative affect by anxious individuals to estimate risk. Journal of Personality and Social Psychology, 5, 1350-1363.

Giesler, R. B., Josephs, R. A., \& Swann, W. B. (1996). Self-verification in clinical depression: The desire for negative evaluation. Journal of Abnormal Psychology, 105, 358-368.

Gilbert, P. (1998). The evolved basis and adaptive functions of cognitive distortions. British Journal of Medical Psychology, 71, 447-463.

Gilboa-Schechtman, E., Foa, E. B., \& Amir, N. (1999). Attentional biases for facial expressions in social phobia: The face-in-the crowd paradigm. Cognition \& Emotion, 13, 305-318.

Gilboa-Schechtman, E., Franklin, M. E., \& Foa, E. B. (2000). Anticipated reactions to social events: Differences among individuals with generalized social phobia, obsessive-compulsive disorder and nonanxious controls. Cognitive Therapy and Research, 24, 731-736.

Gotlib, I. H., \& McCabe, S. B. (1987). Construct accessibility and clinical depression: A longitudinal investigation. Cognition \& Emotion, 1, 199204.

Gotlib, I. H., McLachlan, A. L., \& Katz, A. N. (1988). Biases in visual attention in depressed and nondepressed individuals. Cognition \& Emotion, 2, 185-200.

Gross, J. J. (2002). Emotion regulation: Affective, cognitive, and social consequences. Psychophysiology, 39, 281-291.

Guarnaccia, P. J., \& Rogler, L. H. (1999). Research on culture-bound syndromes: New directions. American Journal of Psychiatry, 156, 1322 1327.

Haenen, M. A., de Jong, P. J., Schmidt, A. J., Stevens, S., \& Visser, L. (2000). Hypochondriacs' estimation of negative outcomes: Domainspecific and responsiveness to reassuring and alarming information. Behaviour Research and Therapy, 38, 819-833.

Haenen, M. A., Schmidt, A. J., Schoenmakers, M., \& van den Hout, M. A. (1997). Tactual sensitivity in hypochondriasis. Psychotherapy and Psychosomatics, 66, 128-132.

Harvey, A., Watkins, E., Mansell, W., \& Shafran, R. (2004). Cognitive behavioural processes across psychological disorders: A transdiagnos- 
tic approach to research and treatment. Oxford, England: Oxford University Press.

Harvey, J. M., Richards, J. C., Dziadosz, T., \& Swindell, A. (1993). Misinterpretation of ambiguous stimuli in panic disorder. Cognitive Therapy and Research, 17, 235-248.

Hassin, R. R. (2005). Nonconscious control and implicit working memory. In R. R. Hassin, J. S. Uleman, \& J. A. Bargh (Eds.), The new unconscious (pp. 196-222). Oxford, England: Oxford University Press.

Helmholtz, H. (1962). Treatise on physiological optics (A. Gullstrand, J. v. Kries, \& W. Nagel, Trans.). New York: Dover. (Original work published 1866)

Herink, R. (Ed.). (1980). The psychotherapy handbook: The A to Z guide to more than 250 different therapies in use today. New York: New American Library.

Hertel, P. T., \& Hardin, T. S. (1990). Remembering with and without awareness in a depressed mood: Evidence of deficits in initiative. Journal of Experimental Psychology, 119, 45-59.

Higgins, E. T., Klein, R., \& Strauman, T. (1985). Self-concept discrepancy theory: A psychological model for distinguishing among different aspects of depression and anxiety. Social Cognition, 3, 51-76.

Hirsch, C. R., \& Matthews, A. (2000). Impaired positive inferential bias in social phobia. Journal of Abnormal Psychology, 109, 705-712.

Hirsch, C. R., Matthews, A., Clark, D. M., \& Williams, R. M. (2003). Self-images play a causal role in social phobia. Behaviour Research and Therapy, 41, 1383-1396.

Hopcroft, J. E., \& Ullman, J. D. (1979). Formal languages and their relation to automata. Reading, MA: Addison-Wesley.

Hull, C. L. (1920). Quantitative aspects of the evolution of concepts. Psychological Monographs, 28(Whole No. 123).

Isen, A. N., \& Gorglione, J. M. (1983). Some specific effects of four affect-induction procedures. Personality and Social Psychology Bulletin, 9, 136-143.

Jackson, D. C., Malmstadt, J. R., Larson, C. L., \& Davidson, R. J. (2000). Suppression and enhancement of emotional responses to unpleasant pictures. Psychophysiology, 37, 515-522.

Jang, K. L., McCrae, R. R., Angleitner, A., Riemann, R., \& Livesley, W. J. (1998). Heritability of facet-level traits in a cross-cultural twin sample: Support for a hierarchical model of personality. Journal of Personality and Social Psychology, 74, 1556-1565.

Johansen, P. V., Brody, H., Paneth, N., Rachman, S., \& Rip, M. (2003). Cholera, chloroform, and the science of medicine: A life of John Snow. Oxford, England: Oxford University Press.

Johnson, E. J., \& Tversky, A. (1983). Affect, generalization, and the perception of risk. Journal of Personality and Social Psychology, 45, 21-31.

Johnson-Laird, P. N. (1983). Mental models: Towards a cognitive science of language, inference, and consciousness. Cambridge, MA: Harvard University Press.

Johnson-Laird, P. N., \& Oatley, K. (2000). The cognitive and social construction of emotions. In M. Lewis \& J. Haviland (Eds.), Handbook of emotions (2nd ed., pp. 458-475). New York: Guilford Press.

Johnson-Laird, P. N., \& Savary, F. (1996). Illusory inferences about probabilities. Acta Psychologica, 93, 69-90.

Jones, M. K., \& Menzies, R. G. (2000). Danger experiences, self-efficacy and insight in spider phobia. Behaviour Research and Therapy, 38, $585-600$.

Kamieniecki, G. W., Wade, T., \& Tsourtos, G. (1997). Interpretive bias for benign sensations in panic disorder with agoraphobia. Journal of Anxiety Disorder, 11, 141-156

Kaney, S., Bowen-Jones, K., Dewey, M. E., \& Bentall, R. P. (1997). Two predictions about paranoid ideation: Deluded, depressed and normal participants' subjective frequency and consensus judgements for positive, neutral and negative events. British Journal of Clinical Psychology, 36, 349-364

Keltner, D., Ekman, P., Gonzaga, G. C., \& Beer, J. (2003). Facial expres- sion of emotion. In R. J. Davidson, K. R. Scherer, \& H. H. Goldsmith (Eds.), Handbook of affective sciences (pp. 415-432). New York: Oxford University Press.

Kessler, R. C., Berglund, P., Demler, O., Jin, R., Merikangas, K. R., \& Walters, E. E. (2005). Lifetime prevalence and age-of-onset distributions of $D S M-I V$ disorders in the National Comorbidity Survey Replication. Archives of General Psychiatry, 62, 593-602.

Kindt, M., van den Hout, M., \& Buck, N. (2005). Dissociation related to subjective memory fragmentation and intrusions but not to objective memory disturbances. Journal of Behavior Therapy and Experimental Psychiatry, 36, 43-59.

Kleinknecht, R. A., Dinnel, D. L., Kleinknecht, E. E., Hiruma, N., \& Harada, N. (1997). Cultural factors in social anxiety: A comparison of social phobia symptoms and taijin kyofusho. Journal of Anxiety Disorders, 11, 157-177.

LaBar, K. S., Gatenby, C., Gore, J. C., LeDoux, J. E., \& Phelps, E. A (1998). Human amygdala activation during conditioned fear acquisition and extinction: A mixed-trial fMRI study. Neuron, 20, 937-945.

Lashley, K. S. (1958). Cerebral organization and behavior. In H. C. Solomon, S. Cobb, \& W. Penfield (Eds.), The brain and human behavior (pp. 1-18). Baltimore: Williams \& Wilkins.

Lavy, E., van den Hout, M. A., \& Arntz, A. (1993). Attentional biases and phobia: Conceptual and clinical issues. Behaviour Research and Therapy, 31, 17-24.

Lazarus, R. S., \& Alfert, E. (1964). Short-circuiting of threat by experimentally altering cognitive appraisal. Journal of Abnormal Psychology, 69, 195-205.

Leahy, R. L. (Ed.). (2004). Contemporary cognitive therapy: Theory, research, and practice. London: Guilford Press.

Lecci, L., \& Cohen, D. J. (2002). Perceptual consequences of illness concern induction and its relation to hypochondriacal tendencies. Health Psychology, 21, 147-156.

LeDoux, J. (1996). The emotional brain: The mysterious underpinnings of emotional life. New York: Simon \& Schuster.

LeDoux, J. (2000). Emotion circuits in the brain. Annual Review of Neuroscience, 23, 155-184

Lee, H. J., Cougle, J. R., \& Telch, M. J. (2005). Thought-action fusion and its relationship to schizotypy and OCD symptoms. Behaviour Research and Therapy, 43, 29-41.

Leon, G. R. (1990). Case histories of psychopathology (4th ed.). Boston: Allyn \& Bacon

Livesley, W. J., Jang, K. L., \& Vernon, P. A. (1993). Genetic and environmental contributions to dimensions of personality disorder. American Journal of Psychiatry, 150, 12-20.

Lundh, L. G., \& Öst, L.-G. (1997). Explicit and implicit memory bias in social phobia: The role of subdiagnostic type. Behaviour Research and Therapy, 35, 1003-1017.

MacLeod, A. K., Tata, P., Kentish, J., \& Jacobsen, H. (1997). Retrospective and prospective cognitions in anxiety and depression. Cognition \& Emotion, 11, 467-479.

MacLeod, C., \& McLaughlin, K. (1995). Implicit and explicit memory bias in anxiety: A conceptual replication. Behaviour Research and Therapy, 33, 1-14.

Maeda, F., \& Nathan, J. H. (1999). Understanding taijin kyofusho through its treatment: Morita therapy. Journal of Psychosomatic Research, 46, $525-530$.

Maidenberg, E., Chen, E., Craske, M., Bohn, P., \& Bytritsky, A. (1996) Specificity of attentional bias in panic disorder and social phobia. Journal of Anxiety Disorders, 10, 529-541.

Mancini, F. (2005). Il disturbo ossessivo compulsivo [The obsessivecompulsive disturbance]. In B. Bara (Ed.), Nuovo manuale di psicoterapia cognitiva (Vol. 2, pp. 98-141). Turin, Italy: Bollati Boringhieri.

Mancini, F., \& Gangemi, A. (2002). Il paradosso nevrotico, ovvero della resistenza al cambiamento [The paradox of neurosis: Resistance to change]. In C. Castelfranchi, F. Mancini, \& M. Miceli (Eds.), Fonda- 
menti di cognitivismo clinico (pp. 156-199). Turin, Italy: Bollati Boringhieri.

Mancini, F., \& Gangemi, A. (2004). Fear of guilt of behaving irresponsibly in obsessive-compulsive disorder. Journal of Behavior Therapy and Experimental Psychiatry, 35, 109-120.

Mancini, F., Gangemi, A., \& van den Hout, M. (2006). Feeling guilty as a source of information about threat and performance. Manuscript submitted for publication.

Mansell, W., \& Clark, D. M. (1999). How do I appear to others? Social anxiety and processing of the observable self. Behaviour Research and Therapy, 37, 419-434.

Mansell, W., Clark, D. M., \& Ehlers, A. (2003). Internal versus external attention in social anxiety: An investigation using a novel paradigm. Behaviour Research and Therapy, 41, 555-572.

Maslow, A. H. (1938). Cases in personality and abnormal psychology. New York: Brooklyn College Press.

Mathews, A., \& MacLeod, C. (1986). Discrimination of threat cues in anxiety states. Journal of Abnormal Psychology, 95, 131-138.

Mathews, A., Richards, A., \& Eysenck, M. (1989). Interpretation of homophones related to threat in anxiety states. Journal of Abnormal Psychology, 98, 31-34.

McCabe, S. B., \& Gotlib, I. H. (1995). Selective attention and clinical depression: Performance on a deployment-of-attention task. Journal of Abnormal Psychology, 104, 241-245.

McCabe, S. B., \& Toman, P. E. (2000). Stimulus exposure duration in a deployment-of-attention task. Effects on dysphoric, recently dysphoric, and nondysphoric. Cognition \& Emotion, 14, 125-142.

McNally, R. J., Amir, N., Louro, C. E., Lukach, B. M., Riemann, B. C., \& Calamari, J. E. (1994). Cognitive processing of idiographic information in panic disorder. Behaviour Research and Therapy, 32, 119-122.

McNally, R. J., \& Foa, E. B. (1987). Cognition and agoraphobia: Bias in the interpretation of threat. Cognitive Therapy and Research, 3, 567581.

McNally, R. J., Foa, E. B., \& Donnell, C. D. (1989). Memory bias for anxiety information in patients with panic disorder. Cognition \& Emotion, 3, 27-44.

Miyake, A., \& Shah, P. (1999). Models of working memory: Mechanisms of active maintenance and executive control. New York: Cambridge University Press.

Miyamoto, J. M., Gonzalez, R., \& Tu, S. (1995). Compositional anomalies in the semantics of evidence. In J. Busemeyer, R. Hastie, \& D. Medin (Eds.), Decision making from a cognitive perspective (pp. 319-383). New York: Academic Press.

Mogg, K., \& Bradley, B. P. (1998). A cognitive-motivational analysis of anxiety. Behaviour Research and Therapy, 36, 809-848.

Mogg, K., Millar, N., \& Bradley, B. P. (2000). Biases in eye movements to threatening facial expression in generalized anxiety disorder and depressive disorder. Journal of Abnormal Psychology, 109, 695-704.

Moretti, M. M., \& Shaw, B. F. (1989). Automatic and dysfunctional cognitive processes in depression. In J. S. Uleman \& J. A. Bargh (Eds.), Unintended thought (pp. 383-421). New York: Guilford Press.

Morris, J. S., Öhman, A., \& Dolan, R. J. (1998, June 4). Conscious and unconscious emotional learning in the human amygdala. Nature, 393, 467-470.

Murray, L. A., Whitehouse, W. G., \& Alloy, L. B. (1999). Mood congruence and depressive deficits in memory: A forced-recall analysis. Memory, 7, 175-196.

Musa, C., Lèpine, J. P., Clark, D. M., Mansell, W., \& Ehlers, A. (2003). Selective attention in social phobia and moderating effect of a concurrent depressive disorder. Behaviour Research and Therapy, 41, 10431054.

Nakamura, K., Kitanishi, K., Miyake, Y., Hashimoto, K., \& Kubota, M. (2002). The neurotic versus delusional subtype of taijin-kyofu-sho: Their DSM diagnoses. Psychiatry and Clinical Neurosciences, 56, 595-601.
Newell, A. (1990). Unified theories of cognition. Cambridge, MA: Harvard University Press.

Nisbett, R. E. (2003). The geography of thought: How Asians and Westerners think differently . . and why. New York: Free Press.

Nunn, J. D., Mathews, A., \& Trower, P. (1997). Selective processing of concern-related information in depression. British Journal of Clinical Psychology, 36, 489-503.

Oatley, K., \& Johnson-Laird, P. N. (1987). Towards a cognitive theory of emotion. Cognition \& Emotion, 1, 29-50.

Oatley, K., \& Johnson-Laird, P. N. (1996). The communicative theory of emotions: Empirical tests, mental models, and implications for social interaction. In L. L. Martin \& A. Tesser, (Eds.), Striving and feeling: Interactions among goals, affect, and self-regulation (pp. 363-393). Mahwah, NJ: Erlbaum.

O'Connor, K. (2002). Intrusions and inferences in obsessive compulsive disorder. Clinical Psychology and Psychotherapy, 9, 38-46.

O'Connor, K., \& Aardema, F. (2003). Fusion or confusion in obsessivecompulsive disorder. Psychological Reports, 93, 227-232.

Ortony, A., \& Turner, T. J. (1990). What's basic about basic emotions? Psychological Review, 97, 315-331.

Öst, L.-G., \& Csatlos, P. (2000). Probability ratings in claustrophobic patients and normal controls. Behaviour Research and Therapy, 38, $1107-1116$.

Oswald, N. C., Waller, R. E., \& Drinkwater, J. (1970). Relationship between breathlessness and anxiety in asthma and bronchitis: A comparative study. British Medical Journal, 2, 14-17.

Owens, K. M. B., Asmundson, G. J. G., Hadjistavropoulos, T., \& Owens, T. J. (2004). Attentional bias toward illness threat in individuals with elevated health anxiety. Cognitive Therapy and Research, 28, 57-66.

Panksepp, J. (1998). Affective neuroscience: The foundations of human and animal emotions. Oxford, England: Oxford University Press.

Panksepp, J. (2005). Affective consciousness: Core emotional feelings in animals and humans. Consciousness and Cognition, 14, 30-80.

Panzarella, C., Alloy, L. B., Abramson, L. Y., \& Klein, K. (1999). Cognitive contributions to mental illness and mental health. In F. T. Durso, R. S. Nickerson, R. W. Schvaneveldt, S. T. Dumais, \& M. T. H. Chi (Eds.), Handbook of applied cognition (pp. 725-755). New York: Wiley.

Pélissier, M.-C., \& O'Connor, K. P. (2002). Deductive and inductive reasoning in obsessive-compulsive disorder. British Journal of Clinical Psychology, 41, 15-27.

Phelps, E. A. (2005). The interaction of emotion and cognition: The relation between the human amygdala and cognitive awareness. In R. R. Hassin, J. S. Uleman, \& J. A. Bargh (Eds.), The new unconscious (pp. 61-76). Oxford, England: Oxford University Press.

Quero, S., Baños, R., \& Botella, C. (1996). Sesgos atencionales y de memoria en el trastorno de angustia [Attentional and memory biases in panic disorder]. Análisis y Modificación de Conducta, 22, 409-433.

Rachman, S. (1993). Obsessions, responsibility, and guilt. Behaviour Research and Therapy, 31, 149-154.

Rachman, S. (1994). The overprediction of fear: A review. Behaviour Research and Therapy, 32, 683-690.

Rachman, S., \& de Silva, P. (1978). Abnormal and normal obsessions. Behaviour Research and Therapy, 16, 233-248.

Rachman, S., \& Hodgson, R. (1980). Obsessions and compulsions. Englewood Cliffs, NJ: Prentice-Hall.

Rachman, S., \& Lopatka, C. (1986a). Match and mismatch in the prediction of fear: I. Behaviour Research and Therapy, 24, 387-393.

Rachman, S., \& Lopatka, C. (1986b). A simple method for determining the functional independence of two or more fears. Behaviour Research and Therapy, 24, 661-664.

Rachman, S., \& Shafran, R. (1999). Cognitive distortions: Thought-action fusion. Clinical Psychology and Psychotherapy, 6, 80-85.

Radomsky, A. S., \& Rachman, S. (1999). Memory bias in obsessivecompulsive disorder. Behaviour Research and Therapy, 37, 605-618.

Rapee, R. M., McCallum, S. L., Melville, L. F., Ravenscroft, H., \& 
Rodney, J. M. (1994). Memory bias in social phobia. Behaviour Research and Therapy, 32, 89-99.

Rauch, S. L., Whale, P. J., Shin, L. M., McInerney, S. C., Macklin, M. L., Lasko, N. B., et al. (2000). Exaggerated amygdala response to masked facial stimuli in posttraumatic stress disorder: A functional MRI study. Biological Psychiatry, 47, 769-776.

Reed, G. (1977). Obsessional cognition: Performance on two numerical tasks. British Journal of Psychiatry, 130, 184-185.

Rhéaume, J., Freeston, M. H., Ladouceur, R., Bouchard, C., Gallant, L., Talbot, F., \& Valliéres, A. (2000). Functional and dysfunctional perfectionists: Are they different on compulsive-like behaviors? Behaviour Research and Therapy, 38, 119-128.

Richards, J. C., Austin, D. A., \& Alvarenga, M. E. (2001). Interpretation of ambiguous interoceptive stimuli in panic disorder and non-clinical panic. Cognitive Therapy and Research, 25, 235-246.

Rivers, W. H. R. (1918, February 2). An address on the repression of war experience. The Lancet, 191(4927), 173-177.

Robinson, L. A., Berman, J. S., \& Neimeyer, R. A. (1990). Psychotherapy for the treatment of depression: A comprehensive review of controlled outcome research. Psychological Bulletin, 108, 30-49.

Rozin, P. (1996). Towards a psychology of food and eating: From motivation to module to model to marker, morality, meaning, and metaphor. Current Directions in Psychological Science, 5, 18-24.

Ruiz-Caballero, J. A., \& González, M. P. (1994). Implicit and explicit memory bias in depressed and nondepressed subjects. Cognition \& Emotion, 8, 555-569.

Ruiz-Caballero, J. A., \& González, M. P. (1997). Effects of level of processing on implicit and explicit memory in depressed mood. Motivation and Emotion, 21, 195-209.

Salkovskis, P. M. (1989). Cognitive-behavioural factors and the persistence of intrusive thoughts in obsessional problems. Behaviour Research and Therapy, 27, 677-682.

Salkovskis, P. M. (1996). The cognitive approach to anxiety: Threat beliefs, safety-seeking behavior, and the special case of health anxiety and obsession. In P. M. Salkovskis (Ed.), Frontiers of cognitive therapy (pp. 48-74). New York: Guilford Press.

Sanavio, E. (1988). Obsessions and compulsions: The Padua Inventory. Behaviour Research and Therapy, 26, 169-177.

Schneider, F., Grodd, W., Weiss, U., Klose, U., Mayer, K. R., Nagele, T., \& Gur, R. C. (1997). Functional MRI reveals left amygdala activation during emotion. Psychiatry Research, 76, 75-82.

Seligman, M. E. P. (1988). Competing theories of panic. In S. Rachman \& J. D. Maser (Eds.), Panic: Psychological perspectives (pp. 321-329). Hillsdale, NJ: Erlbaum.

Shafran, R., Teachman, B. A., Kerry, S., \& Rachman, S. (1999). A cognitive distortion associated with eating disorders: Thought-shape fusion. British Journal of Clinical Psychology, 38, 167-179.

Singh, B. S. (1998). Managing somatoform disorders. Retrieved June 23, 2006, from http://www.mja.com.au/public/mentalhealth/articles/singh/ singh.html

Smeets, G., \& de Jong, P. J. (2005). Belief bias and symptoms of psychopathology in a non-clinical sample. Cognitive Therapy and Research, 29, 377-386.

Smeets, G., de Jong, P. J., \& Mayer, B. (2000). If you suffer from a headache, then you have a brain tumour: Domain specific reasoning "bias" and hypochondriasis. Behaviour Research and Therapy, 38, 763776.

Smith, M. L., Glass, G. V., \& Miller, T. I. (1980). The benefits of psychotherapy. Baltimore: Johns Hopkins University Press.

Snow, J. (1858). On chloroform and other anaesthetics. London: Churchill.

Stanovich, K. E. (1999). Who is rational? Studies of individual differences in reasoning. Mahwah, NJ: Erlbaum.

Stoler, L. S., \& McNally, R. J. (1991). Cognitive bias in symptomatic and recovered agoraphobics. Behaviour Research and Therapy, 29, 539545.

Stopa, L., \& Clark, D. M. (1993). Cognitive processes in social phobia. Behaviour Research and Therapy, 3, 255-267.

Stopa, L., \& Clark, D. M. (2000). Social phobia and interpretation of social events. Behaviour Research and Therapy, 38, 273-283.

Sutherland, N. S. (1976). Breakdown: A personal crisis and a medical dilemma. London: Weidenfeld \& Nicolson.

Szechtman, H., \& Woody, E. (2004). Obsessive-compulsive disorder as a disturbance of security motivation. Psychological Review, 111, 111127.

Tarumi, S., Ichimaya, A., Yamada, S., Umesue, M., \& Kuroki, T. (2004). Taijin kyofusho in university students: Patterns of fear and predispositions to the offensive variant. Transcultural Psychology, 41, 533-546.

Tata, P. R., Leibowitz, J. A., Prunty, M. J., Cameron, M., \& Pickering, A. D. (1996). Attentional bias in obsessional compulsive disorder. Behaviour Research and Therapy, 34, 53-60.

Teasdale, J. D., Taylor, M. J., Cooper, Z., Hayhurst, H., \& Paykel, E. S. (1995). Depressive thinking: Shifts in construct accessibility or in schematic mental models? Journal of Abnormal Psychology, 104, 500-507.

Thodarson, D. S., \& Shafran, R. (2002). Importance of thoughts. In R. O. Frost \& G. Steketee (Eds.), Cognitive approaches to obsessions and compulsions: Theory, assessment, and treatment (pp. 15-28). Boston: Pergamon Press.

Tversky, A., \& Koehler, D. J. (1994). Support theory: A nonextensional representation of subjective probability. Psychological Review, 101, $547-567$.

van den Heuvel, O. A., Veltman, D. J., Groenewegen, H. J., Witter, M. P., Merkelbach, J., Cath, D. C., et al. (2005). Disorder-specific neuroanatomical correlates of attentional bias in obsessive-compulsive disorder, panic disorder, and hypochondriasis. Archives of General Psychiatry, 62, 922-933.

van den Hout, M. A., \& Kindt, M. (2003). Repeated checking causes memory distrust: An explanation of meta-memory problems in compulsive checkers. Behaviour Research and Therapy, 41, 301-316.

Wakefield, J. C. (1992). Disorder as harmful dysfunction: A conceptual critique of DSM-III-R's definition of mental disorder. Psychological Review, 99, 232-247.

Watkins, P. C., Mathews, A., Williamson, D. A., \& Fuller, R. D. (1992), Mood-congruent memory in depression: Emotional priming or elaboration? Journal of Abnormal Psychology, 101, 581-586.

Watkins, P. C., Vache, K., Verney, S. P., \& Mathews, A. (1996). Unconscious mood-congruent memory bias in depression. Journal of Abnormal Psychology, 105, 34-41.

Wells, A. (1997). Cognitive therapy of anxiety disorders: A practice manual and conceptual guide. Chichester, England: Wiley.

Wells, A. (2000). Emotional disorders and metacognition: Innovative cognitive therapy. Chichester, England: Wiley.

Williams, J. M. G., Watts, F., MacLeod, C., \& Mathews, A. (1997). Cognitive psychology and emotional disorders. Chichester, England: Wiley.

Wolpe, J. (1990). The practice of behavior therapy. New York: Pergamon Press.

Woody, S. R., \& Rodriguez, B. F. (2000). Self-focused attention and social anxiety in social phobics and normal controls. Cognitive Therapy and Research, 24, 473-488.

Yurgelun-Todd, D. A., Gruber, S. A., Kanayama, G., Killgore, D. S., Baird, A. A., \& Young, A. D. (2000). fMRI during affect discrimination in bipolar affective disorder. Bipolar Disorder, 2, 237-248.

Received May 10, 2005

Revision received April 17, 2006

Accepted May 23, 2006 